\title{
Variations Associated with Cores and Gaps of a Pacific Narrow Cold Frontal Rainband
}

\author{
DAVID P. JORGENSEN \\ NOAA/National Severe Storms Laboratory, Boulder, Colorado \\ ZhAOXIA PU \\ Goddard Earth Sciences and Technology Center, University of Maryland, Baltimore, Baltimore, and NASA Goddard Space Flight Center, \\ Greenbelt, Maryland \\ P. Ola G. Persson \\ CIRES-University of Colorado, and NOAA/Environmental Technology Laboratory, Boulder, Colorado
}

WeI-KuO TAO

NASA Goddard Space Flight Center, Greenbelt, Maryland

(Manuscript received 17 January 2003, in final form 22 April 2003)

\begin{abstract}
A NOAA P-3 instrumented aircraft observed an intense, fast-moving narrow cold frontal rainband (NCFR) as it approached the California coast on 19 February 2001 during the Pacific Coastal Jets Experiment. Airborne Doppler radar data obtained while the frontal system was well offshore indicated that a narrow ribbon of very high radar reflectivity convective cores characterized the rainband at low levels with echo tops to $\sim 4-5 \mathrm{~km}$, and pseudo-dual-Doppler analyses showed the low-level convergence of the prefrontal air. The NCFR consisted of gaps of weaker reflectivity and cores of stronger reflectivity along its length, perhaps as a result of hydrodynamic instability along its advancing leading edge. In contrast to some earlier studies of cold frontal rainbands, densitycurrent theory described well the motion of the overall front. The character of the updraft structure along the NCFR varied systematically along the length of the precipitation cores and in the gap regions. The vertical shear of the cross-frontal low-level ambient flow exerted a strong influence on the updraft character, consistent with theoretical arguments developed for squall lines describing the balance of vorticity at the leading edge. In short segments at the northern ends of the cores, the vertical wind shear was strongest with the updrafts and rain shafts more intense, narrower, and more erect or even downshear tilted. At the southern ends of the cores and just north of the gaps, the wind shear weakened with less intense updrafts that tilted upshear and contained a broader band of rainfall. Simulations using the nonhydrostatic nested grid version of the fifth-generation Pennsylvania State UniversityNational Center for Atmospheric Research (PSU-NCAR) Mesoscale Model (MM5) are used to investigate the core and gap regions, focusing on the relationship between the character of the modeled updrafts and the balance between the cold-air-induced vorticity and the prefrontal ambient shear vorticity. The cold air behind the NCFR, which forces new convection along its leading edge, is probably maintained by large-scale advection of cold air plus evaporative cooling processes within the heavy rain region of the NCFR. Observations confirm the model results; that is, that the updraft character depends on the balance of vorticity at the leading edge. Downshear-tilted updrafts imply that convection at the northern ends of cores may weaken with time relative to the frontal segments at the southern ends, because inflow air would be affected by passage through the heavy rain region before ascent. A mechanism for line modification is thus implied.
\end{abstract}

\section{Introduction}

The rainfall patterns within extratropical cyclones are usually organized in the form of mesoscale rainbands (Houze et al. 1976; Rutledge and Hobbs 1984). Of the six main types of rainbands classified by Hobbs (1978),

Corresponding author address: David P. Jorgensen, NOAA/NSSL/ MRAD-Boulder, Mail Code: N/C/MRD, 325 Broadway, Boulder, CO 80305-3328.

E-mail: David.P.Jorgensen@noaa.gov the most intense rainfall rates are usually associated with narrow cold frontal rainbands (NCFRs), which are a few kilometers wide and usually found close to the position of the surface cold front. Studies of NCFRs with Doppler radars have shown that they are associated with strong but relatively shallow updrafts of up to $20 \mathrm{~m} \mathrm{~s}^{-1}$ in magnitude (Carbone 1982; Hobbs and Persson 1982; Parsons 1992) near the leading edge of the surface front. The strong updrafts occur in the absence of appreciable potential instability. The radar echo tops are often only 
$\sim 4-5 \mathrm{~km}$ above ground level (AGL). The convective cells within the NCFR are often severe (heavy rain, hail, strong surface winds, tornadoes, etc.) in spite of their shallow nature, and sometimes exhibit gravity-currentlike structures and motion (Carbone 1982; Parsons et al. 1987; Koch and Kocin 1991; Braun et al. 1997). In fact, the NCFR studied here produced small hail (or perhaps graupel) and heavy rain along the California coast at landfall, even though it was particularly difficult to detect by National Weather Service coastal radars due to its shallowness.

The horizontal radar reflectivity depiction (James and Browning 1979; Hobbs and Biswas 1979) associated with the NCFR, rather than being strictly two-dimensional and continuous, has often exhibited breaks or gaps associated with pronounced bowing in the direction of propagation. Usually, the precipitation cores are observed to be oriented at a slight angle with respect to the orientation of the synoptic cold front (Hobbs and Persson 1982; Wakimoto and Bosart 2000). The gap regions of some NCFRs have been observed to be of various sizes (James and Browning 1979). Locatelli et al. (1995) termed gaps greater that $10-12 \mathrm{~km}$ as "large" gaps and suggested that they may be dynamically different from smaller gaps. Wakimoto and Bosart (2000) provided finescale kinematic observations of these large gaps using airborne Doppler radar. Their analysis clearly showed that the gap regions were areas devoid of strong updrafts and associated with weak surface wind discontinuities. The maximum core reflectivity could be displaced downwind from the core updraft and could be collocated with the weakest surface discontinuity, a refinement to earlier NCFR analysis by Hobbs and Persson (1982). Horizontal shearing instabilities (Haurwitz 1949) along the leading edge of the advancing cold front often has been advanced as the explanation for forming the wavelike gap and core structure of the NCFR (Matejka et al. 1980), although other mechanisms, such as trapped gravity waves (Brown et al. 1999) or perhaps differential advection of precipitation particles by corerelative winds, could lead to the observed NCFR structure (Locatelli et al. 1995) as well.

Two-dimensional cross-frontal sections through the leading edges of NCFRs often reveal a gravity-currentlike structure (Koch and Kocin 1991; Chen et al. 1997) similar to that observed across midlatitude, continental squall lines (Charba 1974). The gravity current, fed by low-level cold air advection and evaporative cooling from the intense NCFR precipitation, helps maintain the NCFR updraft through the balance of the solenoidally forced vorticity within the gravity current and the vorticity produced by strong environmental vertical wind shear (Rotunno et al. 1988). High-resolution mesoscale numerical simulations (Chen et al. 1997) of NCFRs have replicated many of their observed structural features, including the low-level gravity current. However, limitations in the model's cloud microphysical parameterization and grid resolution may have precluded using the model to test the hypothesis that evaporative cooling was important in maintaining the gravity current and associated frontal contraction and NCFR structure (Koch 1999).

Since the NCFR studied here exhibited many gravitycurrent characteristics, we observationally test the relationship between the NCFR updraft and the balance between the solenoidally forced vorticity within the gravity current and the vorticity produced by strong vertical wind shear associated with the low-level jet ahead of the NCFR. Furthermore, we examine how this relationship changes along the precipitation cores and in the gap regions, providing evidence of a possible mechanism by which the core and gap regions can evolve on a timescale of a few hours. These objectives are achieved through analysis of the pseudo-dual-Doppler radar data, flight level in situ data, and dropsonde measurements obtained on 19, February 2001 from a National Oceanic and Atmospheric Administration (NOAA) instrumented WP-3D aircraft operating in the northwest Pacific during the Pacific Landfalling Jets Experiment in January-February 2001 (PACJET-2001). We further supplement the Doppler analyses with numerical mesoscale model results using the fifth-generation Pennsylvania State University-National Center for Atmospheric Research (Penn State-NCAR) Mesoscale Model (MM5) to explore the relationships between lowlevel processes and the gap regions of the NCFR.

In section 2, we describe the aircraft data and the analysis method. Section 3 describes the overall structure of the NCFR and its environment, with an emphasis on the features related to the precipitation cores and gaps. In this section, we also relate the observed updraft tilts to the squall-line theory of Rotunno et al. (1988, henceforth referred to as RKW). In section 4, we utilize a successful numerical simulation of this case to examine aspects not directly available from the observations, specifically the depth of the postfrontal cold air and its alongfront variation. In section 5, we summarize the findings and include a discussion on the implication of these results for the evolution of the gap-core structure of NCFRs.

\section{Aircraft data and analysis approach}

The overarching goal of PACJET is to develop and test methods to improve short-term $(0-24 \mathrm{~h})$ forecasts of damaging weather on the U.S. west coast in landfalling winter storms emerging from the data-sparse $\mathrm{Pa}$ cific Ocean. Specifically, PACJET provides the datasets with which to improve understanding of landfalling storms, as well as providing unique data to forecasters for real-time predictions. (For more information on PACJET, see the Web site: http://www.etl.noaa.gov/ programs/2002/pacjet/).

The primary observational platform used in this study is the NOAA P-3 aircraft with its vertically scanning $\mathrm{X}$-band (wavelength $3.22 \mathrm{~cm}$ ) Doppler radar (Jorgensen 
TABLE 1. Characteristics of the NOAA P-3 weather radars.

\begin{tabular}{|c|c|c|}
\hline Parameter & Doppler tail radar & Lower fuselage radar \\
\hline Antenna rotation $\operatorname{radar}\left({ }^{\circ} \mathrm{S}^{-1}\right)$ & 60 & 12 \\
\hline Transmitter wavelength $(\mathrm{cm})$ & 3.22 & 5.59 \\
\hline Transmitter pulse length $\left(\mu \mathrm{s}^{-1}\right)$ & $0.5,0.375$, or 0.25 & 6 \\
\hline Receiver minimum detectable signal $(\mathrm{dBm})$ & -111 & -109 \\
\hline Pulse repetition frequency $(\mathrm{Hz})$ & $3200 / 2133$ & 200 \\
\hline Sweep angle resolution $\left({ }^{\circ}\right)$ & 0.6 & 1.92 \\
\hline Peak transmitted power $(\mathrm{kW})$ & 60 & 70 \\
\hline Horizontal beam width $\left(^{\circ}\right)$ & 2.02 & 1.35 \\
\hline Vertical beam width $\left({ }^{\circ}\right)$ & 2.04 & 4.1 \\
\hline Gain, main beam $(\mathrm{dB})$ & 40 & 37.5 \\
\hline Gain, sidelobes $(\mathrm{dB})$ & Hor: -56.6 ; Ver: -41.6 & -23.0 \\
\hline Pulses averaged per radial & 32 & 32 \\
\hline Nyquist (unambiguous) velocity $\left(\mathrm{m} \mathrm{s}^{-1}\right)$ & 51.4 & \\
\hline Nyquist (unambiguous) range $(\mathrm{km})$ & 46.8 & 749.5 \\
\hline Gate spacing $(\mathrm{m})$ & 150 & 750 \\
\hline
\end{tabular}

et al. 1983). The P-3 was deployed from its PACJET base of operations in Monterey, California. In addition to its Doppler radar and wide variety of in situ sensors, the NOAA P-3 is also equipped with a horizontally scanning lower fuselage C-band (wavelength $5.59 \mathrm{~cm}$ ) radar for mapping of radar reflectivity to a range of about $400 \mathrm{~km}$ from the aircraft. The various parameters associated with the P-3 radars are shown in Table 1 .

The NOAA P-3 airborne Doppler radar (Fig. 1) is an $\mathrm{X}$-band, vertically scanning radar mounted in the tail section of the P-3 that uses the fore/aft scanning technique (FAST; Jorgensen et al. 1996) to alternately scan the antenna fore and aft by about $20^{\circ}$ from a plane perpendicular to the flight track during a period of two full antenna rotations. As the aircraft flies a relatively straight flight path, the antenna sweeps out a three-dimensional volume with the fore and aft beams intersecting at approximately $40^{\circ}$ angles. The horizontal velocity is estimated from these two estimates in the vertical region defined by $\pm 45^{\circ}$ elevation angle. Restricting the elevation angle to $\pm 45^{\circ}$ minimized the deleterious effects of uncertainties in terminal fall speed on the horizontal wind estimate. The radar uses a batch-mode "staggered pulse-repetition frequency (PRF)" approach to extend the unambiguous radial (Nyquist) velocity using two PRFs (Jorgensen et al. 2000). The two PRFs used in this study were 3200 and $2133 \mathrm{~s}^{-1}$, which produced an extended Nyquist interval of $51.6 \mathrm{~m} \mathrm{~s}^{-1}$; hence, there were few "folds" in the radar data that had to be manually corrected. The very small number of processor dealiasing mistakes $(\sim 3 \%$ of the total radar bins) were removed using the NCAR SOLO radar editing software package. Following editing, three-dimensional winds were constructed using the pseudo-dualDoppler methodology described in Jorgensen et al. (1996). The Doppler data from 19 February were collected with the antenna in sector scanning mode, so that the resulting horizontal data spacing was $\sim 700 \mathrm{~m}$. The Doppler data were interpolated to Cartesian grids with a spacing $\Delta x=\Delta y=0.7 \mathrm{~km}$ and $\Delta z=0.5 \mathrm{~km}$. The vertical grid levels were constructed relative to mean sea level (MSL). Vertical velocity was estimated from vertical integration of horizontal divergence estimates. The integration was performed from the top of the echo (where $w=0$ is assumed) to the surface. An O'Brien (1970) divergence correction was made to the vertical column to ensure that $w=0$ at the ground. A two-step Leise filter (Leise 1981) was applied to the velocity data prior to computation of the vertical velocity to remove artifacts of wavelength less that about $4 \Delta x$ and to retain greater than $90 \%$ of the energy of features with wavelength $>8 \Delta x$.

The maximum range of the radar is about $45 \mathrm{~km}$, which implies a maximum time displacement between fore and aft scans of about $4 \mathrm{~min}$. During that time, as well as for the duration of each flight leg that comprises the complete volume scan, the weather within the analysis domain is assumed to be "stationary." Stationarity over the 4-10 min required to complete the volume scan is a fairly common assumption for airborne and groundbased Doppler radar studies. Nevertheless, this assumption is a limiting factor in interpreting the data collected on relatively quickly evolving systems, such as individual convective storm cells.

To determine NCFR motion, a sequence of lower fuselage radar composites was examined over about a 6$\mathrm{h}$ period to determine motion of the leading edge. Various "bows," "gaps," or "kinks" in the NCFR could be tracked reliably for several hours, and their displacements aided in the determination of overall NCFR motion. The NCFR studied here was moving relatively rapidly: toward $053^{\circ}$ at $18 \mathrm{~m} \mathrm{~s}^{-1}$ over the approximately 6 -h duration of the P-3 investigation. The analysis grid was moved to compensate for this system motion, and wind vectors displayed are relative to the moving system. At various times during the flight, individual convective cores or elements of the NCFR were seen moving slightly differently than this mean NCFR motion. The motion vector of those cores or elements was usually slightly faster or slower than the mean NCFR motion by an average of about $\pm 15^{\circ}$ in direction and \pm 2 $\mathrm{m} \mathrm{s}^{-1}$ in speed. The effect of using this core-relative 

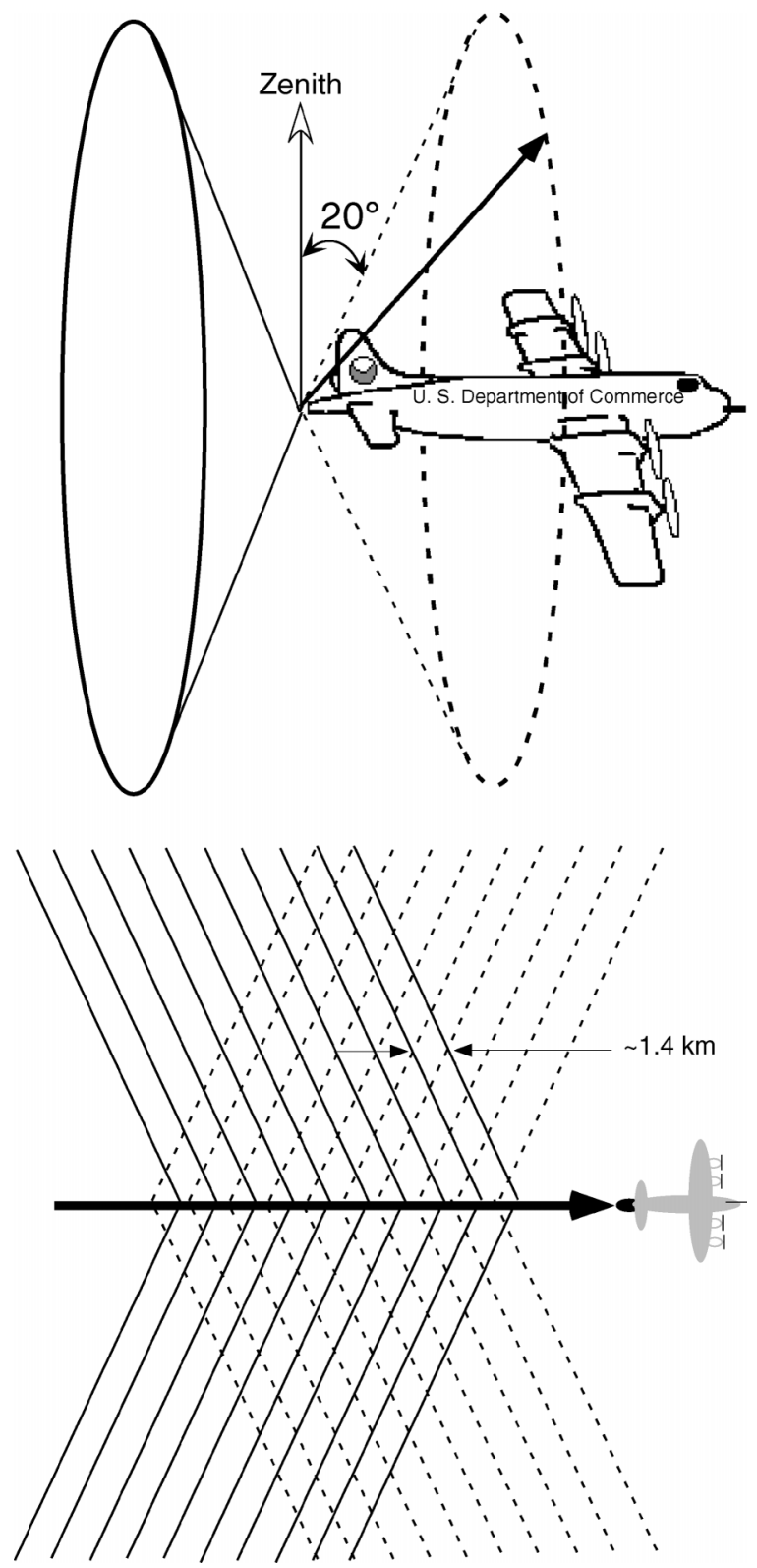

FIG. 1. Scanning geometry of the NOAA P-3 tail-mounted X-band Doppler radar. The antenna scans by alternately looking forward and aft, $20^{\circ}$ from a plane perpendicular to the aircraft's (top) longitudinal axis. (bottom) Projection of the fore and aft scans on a horizontal plane. Where the beams intersect, a horizontal wind estimate can be made. The horizontal data spacing of intersecting beams is proportional to the product of the aircraft's ground speed and antenna rotation rate. For the P-3, with a $10 \mathrm{rpm}$ rotation rate and $\sim 120 \mathrm{~m} \mathrm{~s}^{-1}$ ground speed, the spacing is nominally $\sim 1.4 \mathrm{~km}$. If the antenna is scanned toward only one side of the aircraft (sector scanning) the spacing can be reduced to $\sim 700 \mathrm{~m}$.

motion, rather than the mean NCFR motion, was evaluated for one flight leg segment, where the difference between the two motions was the greatest (i.e., about $20^{\circ}$ in direction and $5 \mathrm{~m} \mathrm{~s}^{-1}$ in speed). The differences in the pseudo-dual-Doppler wind analyses and derived fields such as vertical velocity were slight with use of core-relative motion. Rather than compute separate core-relative motions for each flight leg segment, as was done by Braun et al. (1997) in their study of an offshore NCFR in 1993 using the same P-3; the mean motion was utilized to facilitate comparisons between different time periods.

The radar reflectivity field was determined by taking the maximum of the fore and aft scans at each Cartesian point. An estimate of the precipitation fall speed was subtracted from the radial wind estimates by estimating the component of fall speed into the beam. The fall speeds were estimated using two empirical relationships between terminal fall speed and radar reflectivity: one for rain (Joss and Waldvogel 1970) applied below 1.55 $\mathrm{km} \mathrm{MSL}$ and one for snow (Atlas et al. 1973) applied above $2.05 \mathrm{~km}$ MSL. Between 1.55 and $2.05 \mathrm{~km}$ the terminal fall speed was determined as a weighted sum of the snow and rain relationships. The choice of heights to apply these relationships were determined by locating the height of the bright band on reflectivity cross sections (e.g., Fig. 14). Ahead of the front the brightband height was determined to be $\sim 1.80 \mathrm{~km}$, behind the front it was observed to be $\sim 1.00 \mathrm{~km}$. Since the aircraft was flying ahead of the front, the choice of heights to apply the reflectivity-fall speed relationship was based on the height of the bright band ahead of the front where the elevation angles of the antenna were the steepest. Across the front, where the freezing level dropped to $\sim 1.00$ $\mathrm{km}$, the elevation angles decreased to near horizontal where the component of fall speed motion was near negligible. The effect of misapplying the freezing-level transition across the front was tested with a series of analyses where the transition altitude was varied from 1.8 down to $1.0 \mathrm{~km}$. Very little change in the wind fields was seen in the different syntheses.

\section{Overall NCFR structure from aircraft observations}

The P-3 departed Monterey at 0134 UTC 19 February and arrived in the vicinity of the NCFR at about 0320 UTC. The NCFR was intercepted by the P-3 approximately $560 \mathrm{~km}$ from its base at Monterey, California, over the eastern North Pacific Ocean. The P-3 monitored the NCFR, using a variety of Doppler legs, ascent/descent soundings, and low-level flux stacks until returning to Monterey at 0940 UTC, just ahead of the heavy rainfall of the NCFR at landfall.

\section{a. NCFR environment}

Figure 2 shows the 0000 UTC 19 February 2001 500hPa analyses from NOAA's National Centers for Environmental Prediction (NCEP). Figure 3 shows the sea level pressure analysis at 0600 UTC 19 February, and Fig. 4 shows an infrared satellite image at 0400 UTC, about the time the aircraft had begun its Doppler flight 


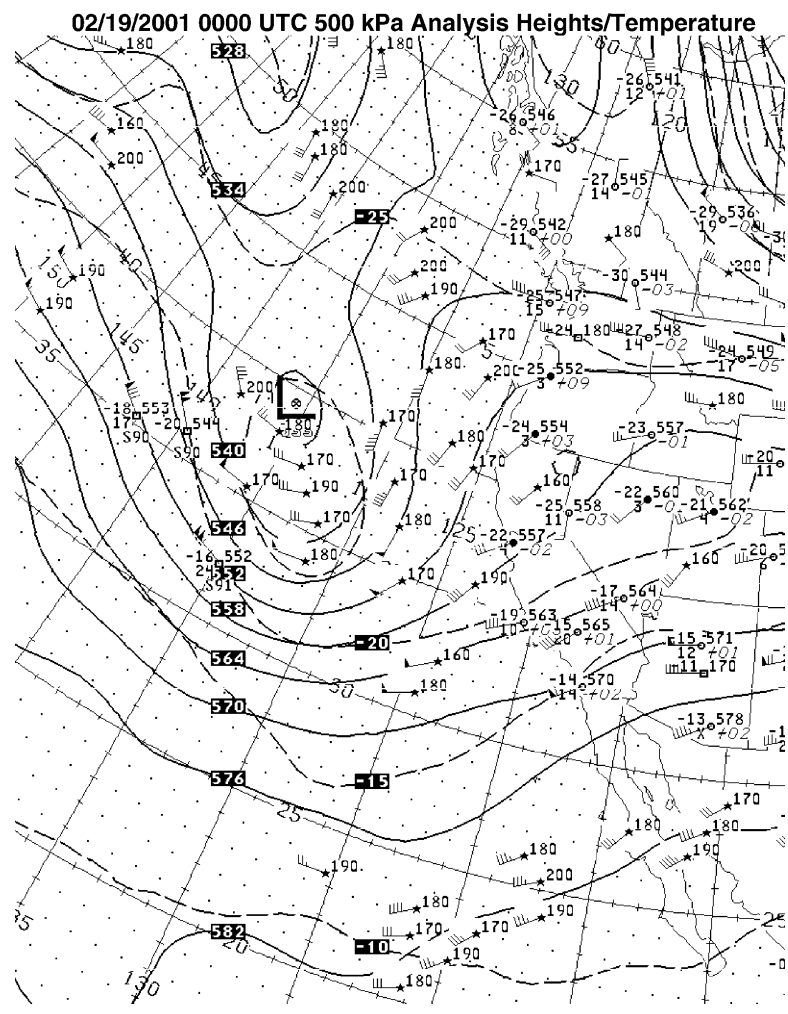

FIG. 2. Geopotential height (decameters, solid line) and temperature $\left({ }^{\circ} \mathrm{C}\right.$, dashed line) analyses at $500 \mathrm{hPa}$ for 0000 UTC $19 \mathrm{Feb} 2001$.

pattern investigation. The advancing cold front (Fig. 3) marked the surface position of the NCFR, which was situated ahead of a 500-hPa-deep occluded low to the northwest (Fig. 2). NCEP's surface frontal position at 0600 UTC was reasonably close (within about $0.5^{\circ}$ of longitude at $35^{\circ} \mathrm{N}$ latitude) to where the P-3 encountered the front at 0600 UTC. Westerly to west-southwesterly surface winds were observed by ships to the west of the front. At landfall near the San Francisco Bay area and southward, the frontal system produced heavy rain and strong surf along the coast.

The NCFR existed in an environment virtually devoid of strong conditional convective instability yet possessing high low-level shear. A sounding constructed by compositing the descent in situ observations by the P3 at 0250 UTC (below $500 \mathrm{hPa}$ ) with the $0000 \mathrm{UTC}$ radiosonde launched at Oakland, California (data above $500 \mathrm{hPa}$ ) is shown in Fig. 5. The P-3 descent was about $50 \mathrm{~km}$ to the east of the leading edge of the NCFR in the warm sector (location of sounding is noted as "PreFrontal Sounding (S)" on the radar image shown in Fig. $6)$. The convective available potential energy (CAPE) was only $\sim 22 \mathrm{~J} \mathrm{~kg}^{-1}$, yet the surface winds were southerly at about $15 \mathrm{~m} \mathrm{~s}^{-1}$, turning to southwesterly at near $25 \mathrm{~m} \mathrm{~s}^{-1}$ by $700 \mathrm{hPa}$. Such low instability/high shear soundings are characteristic of NCFR environments (Houze et al. 1976).

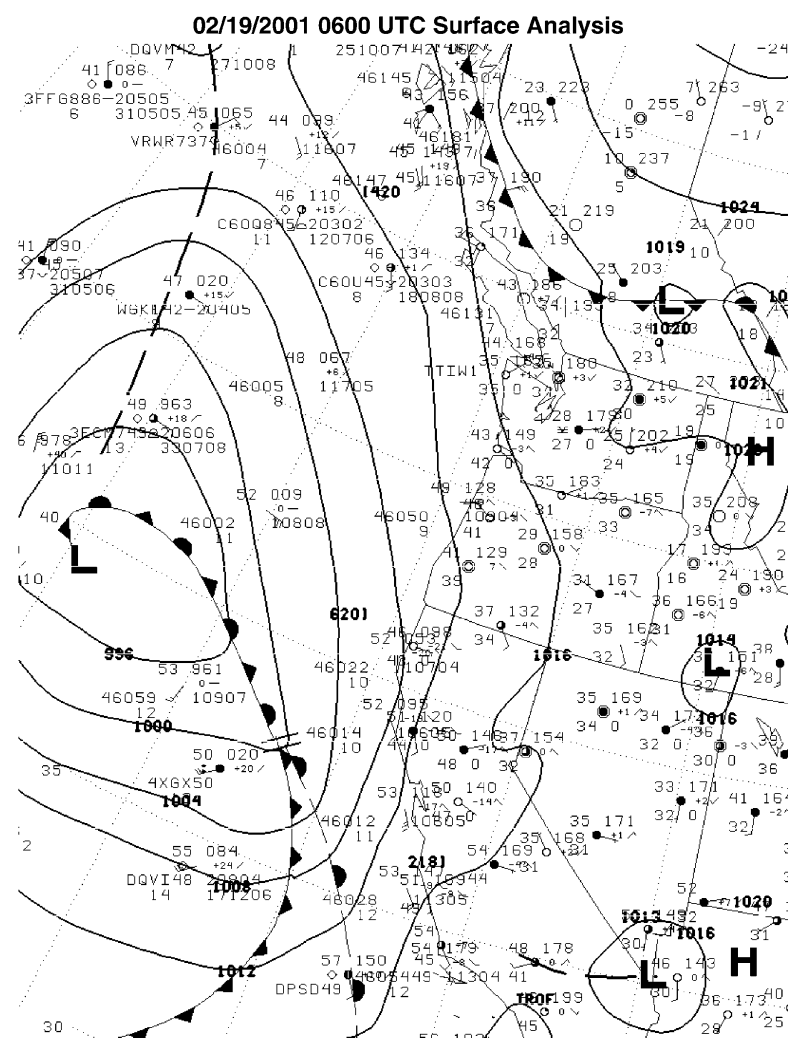

FIG. 3. Sea level pressure (mb) analyses for 0600 UTC 19 Feb 2001

\section{b. Precipitation plan-view perspective}

The $\mathrm{P}-3 \mathrm{~s}$ lower fuselage radar (LF) composite over a 34-min period indicates the extensive horizontal extent of the NCFR (Fig. 6). The horizontal length of the NCFR was quite large with a ribbon of high reflectivity extending over $200-300 \mathrm{~km}$ in length with lighter precipitation ahead of (to the east) and behind (to the west) the surface frontal position. Maximum reflectivity of the core cells often exceeded $55 \mathrm{dBZ}$. The narrow ribbon of high reflectivity ( $>45-50 \mathrm{dBZ}$ ) indicating the position of the NCFR was often not continuous, but broken by periodic gap regions (or kinks) of lighter reflectivity indicating breaks in the NCFR with a spacing between the gaps of 50-75 km. Hobbs and Persson (1982) and Wakimoto and Bosart (2000) also noted the discontinuous nature of the precipitation cores of NCFRs.

Wakimoto and Bosart (2000) found that there was about a $20^{\circ}$ clockwise angle of rotation between the average line defining the cold frontal position and the long axis of the precipitation cores making up the line. For this NCFR, however, we lack the low-level data to determine the precise location of the surface cold front and the orientation of the cores to that position.

\section{c. Environmental wind shear characteristics}

The along-frontal character of the environment ahead of the NCFR is shown in Figs. 7 and 8. In Fig. 7, shallow 


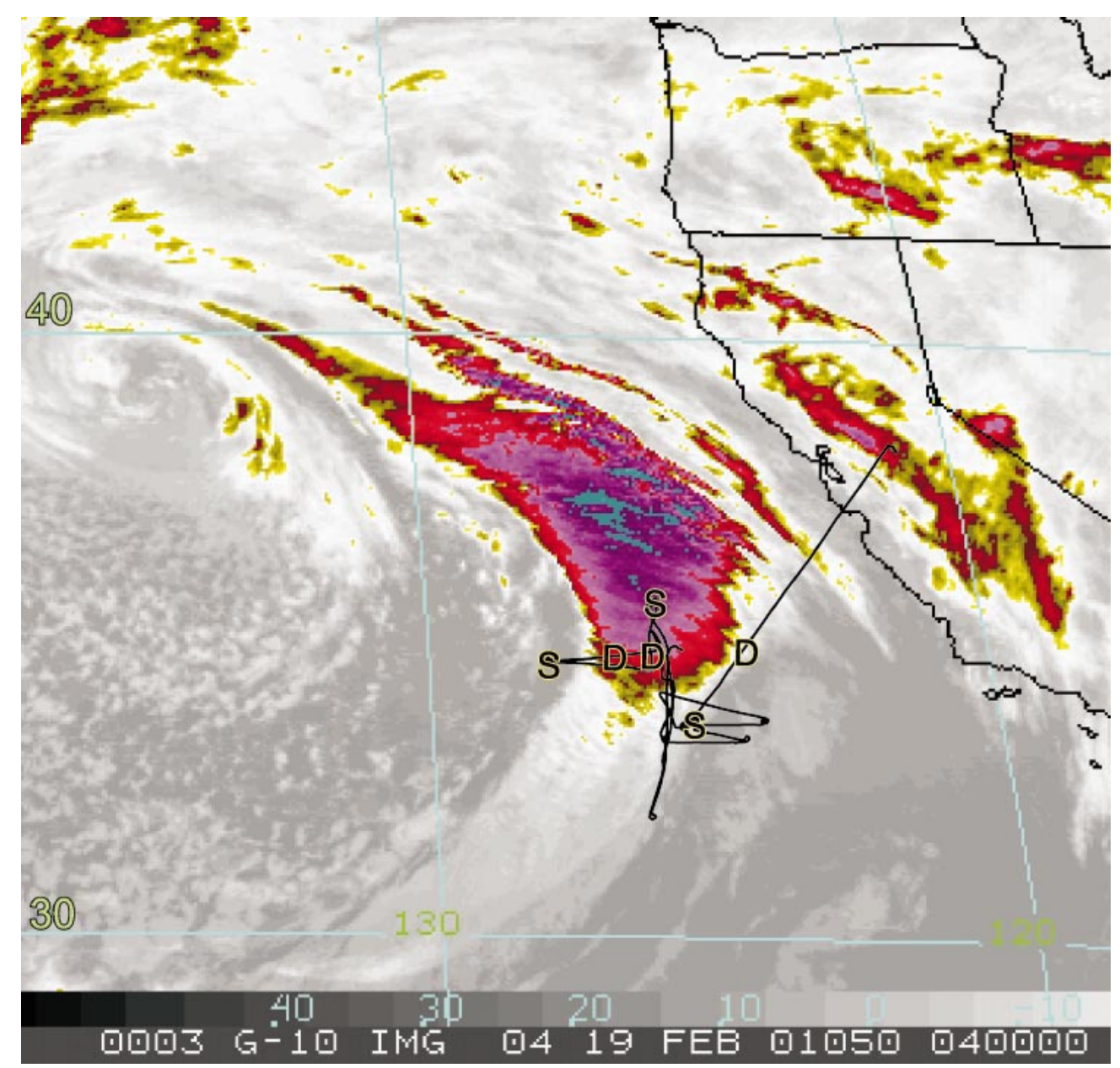

FIG. 4. Infrared satellite images from the GOES-10 satellite at 0400 UTC 19 Feb 2001. The color scale for cloud-top temperature $\left({ }^{\circ} \mathrm{C}\right)$ is at the bottom. The black line is the P-3 track. The S symbol indicates the location of P-3 ascent/descent soundings and the D symbol shows the location of dropsondes. The flight track and dropsonde locations have been spatially adjusted to account for the NCFR motion.

cross sections constructed from aircraft in situ measurements along its northward track in the warm sector $3-8 \mathrm{~km}$ to the east of the NCFR reveal the low-level alongfront thermodynamic variations. The virtual potential temperature shows a statically stable atmosphere in the lowest $1500 \mathrm{~m}$ and a slow but steady decrease of virtual potential temperature in the lowest $1500 \mathrm{~m}$ along the south-to-north track (not shown). The equivalent potential temperature shows that the bottom of the layer of potential instability is near $400 \mathrm{~m}$ to the south and rises to near $900 \mathrm{~m}$ to the north (Fig. 7). The lowlevel jet maximum is near the base of this potentially unstable layer, and reaches a maximum in the alongfront direction between NCFR gaps 2 and 3 near the northern end of the precipitation core and the point of furthest eastward advance of the NCFR (see Fig. 6). The aircraft measurements at $290 \pm 20 \mathrm{~m}$ height along this track (Fig. 8) suggest that the alongfront decreases in temperature, mixing ratio, and wind direction are generally steady with no variations obviously correlated with the alongfront variations in reflectivity associated with the precipitation cores. The alongfront wind speed, however, does show variations with a scale of about $50 \mathrm{~km}$.

A total of nine aircraft sounding profiles were obtained during the P-3 flight. Eight profiles were obtained ahead of the convective line and one behind. Of the eight profiles in front of the line, two had a height range from 300 to $5500 \mathrm{~m}$ and the other six had a height range of 150-1600 m. The postfrontal profile had a range of $300-5500 \mathrm{~m}$. In a front-relative sense, the profiles are spaced 20-200 km ahead of and behind the front and at various locations along the front. The profiles are shown in Fig. 9 for the 300-5500-m-height range, of which two are ahead [denoted Pre-Frontal (N) and PreFrontal (S) on the LF radar plot of Fig. 6] of the line and one is behind (marked Post-Frontal). Of the two located ahead of the NCFR, the Pre-Frontal (S) one was obtained $200 \mathrm{~km}$ further south than the Pre-Frontal (N) profile. The post-frontal profile was located in a northsouth position roughly midway between the two pre- 


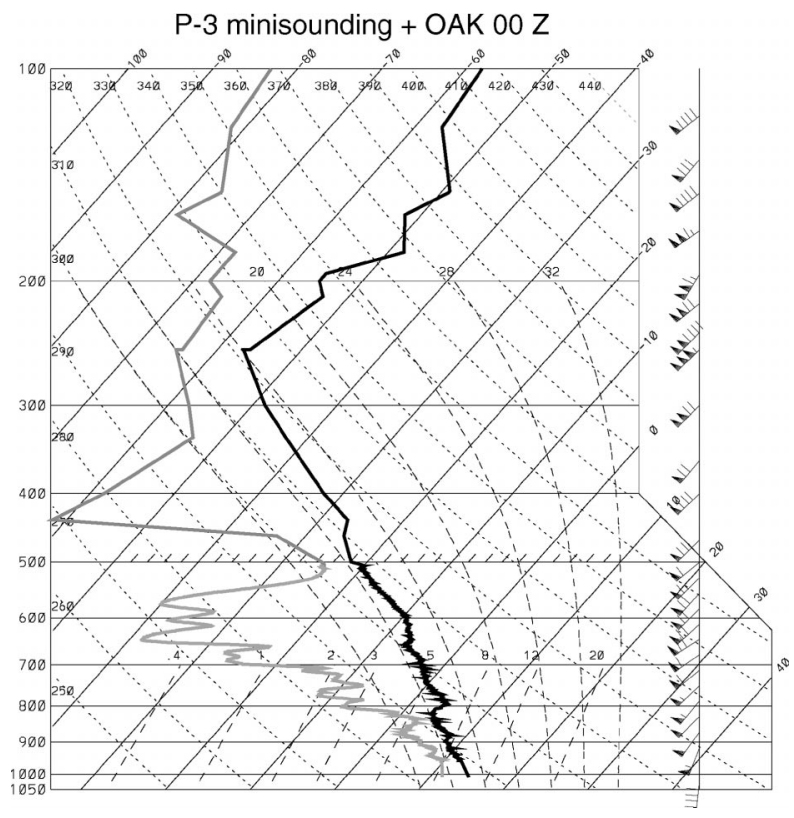

FIG. 5. Skew $T-\log p$ plot of a composite sounding constructed by combining data from a P-3 descent from $500 \mathrm{hPa}$ at 0250 UTC with data from the 0000 UTC 19 Feb 2001 radiosonde launched at Oakland, CA. The descent sounding was located near $34.0^{\circ} \mathrm{N}, 125.4^{\circ} \mathrm{W}$, about $\sim 80 \mathrm{~km}$ to the east (ahead) of the NCFR (shown as the spiral ahead of the line in Fig. 6).

frontal profiles. Since the NCFR had nearly a northsouth orientation at the time of the investigation, the zonal $u$ and meridional $v$ wind profiles approximate the wind components perpendicular to and along the NCFR, respectively. Examination of these profiles indicates differences in both the cross-frontal and along-frontal directions. Far from being homogeneous, the NCFR environment contained substantial differences in the north-south direction. For instance, the along-frontal low-level jet (LLJ) ahead of the NCFR is strongest near the center of the NCFR (in the $v$ component or alongfront direction), reaching $32 \mathrm{~m} \mathrm{~s}^{-1}$. In the two prefrontal profiles shown, the LLJ has a velocity of $24-29 \mathrm{~m} \mathrm{~s}^{-1}$. It is lower in altitude to the south (about $500 \mathrm{~m}$ ) and higher to the north $(1100 \mathrm{~m})$. The air ahead of the convective line is potentially unstable $\left(\partial \theta_{e} / \partial z<0\right)$ up to $3-4 \mathrm{~km}$, where $\theta_{e}$ is the equivalent potential temperature, with the potential instability greater to the south $\left(\partial \theta_{e} / \partial z=-9 \mathrm{~K} / 3000 \mathrm{~m}\right)$ than to the north $\left(\partial \theta_{e} / \partial z=\right.$ $-2 \mathrm{~K} / 3500 \mathrm{~m})$. However, the prefrontal air is statically stable $(\partial \theta / \partial z>0)$, even near the surface (e.g., see Fig. $5)$. Note, however, that the prefrontal air had lower $\theta_{e}$ values below above $800 \mathrm{~m}$ to the north than to the south but higher values about $800 \mathrm{~m}$, and that the midlevel winds were weaker to the south. Behind the front, the air is cooler and drier at all levels. The postfrontal air is potentially unstable to about $2 \mathrm{~km}$, and is statically neutral in the lowest $500 \mathrm{~m}$ (not shown). The presence of small convective clouds in the postfrontal air observed by onboard personnel, and by satellite (Fig. 4), is evidence of this low-level postfrontal instability. The rear inflow jet in $u$ peaked at about $1 \mathrm{~km}$ with a value of $\sim 16 \mathrm{~m} \mathrm{~s}^{-1}$.

\section{d. Kinematic structure}

Figure 10 shows the reflectivity and Doppler wind structure of the NCFR at $1.0 \mathrm{~km}$ MSL in the domain labeled A in Fig. 6. The same fields are displayed slightly higher at $1.75 \mathrm{~km}$ MSL in Fig. 11. At the time of observation the NCFR was oriented approximately north-south with several distinct bows toward the east in the line. Three such bows are shown in Fig. 10 at approximate locations of $y=6 \mathrm{~km}, y=36 \mathrm{~km}$, and $y$ $=94 \mathrm{~km}$. The apex of each bow was associated with an enhancement of low-level radar reflectivity and a larger component of westerly rear inflow behind the line. The breaks in the NCFR were also associated with rear echo trenches in the stratiform rearward reflectivity. Slightly higher in the system, (Fig. 11) the flow behind the line reverses from westerly to southerly or even easterly, depending on location relative to the bows in the line. In general at $1.75 \mathrm{~km}$ MSL the regions just north of the bow apexes are locations of enhanced front to rear flow, while at $1.00 \mathrm{~km} \mathrm{MSL}$ the bow regions are locations of strongest rear to front flow. The line structure for the region B in Fig. 6 is shown in Fig. 12 at $1.00 \mathrm{~km} \mathrm{MSL}$ and in Fig. 13 at $1.75 \mathrm{~km}$ MSL. A bow in the NCFR appears at approximately $y=29 \mathrm{~km}$ with gaps or weaker reflectivity just south and north of it. Enhanced front to rear flow on either side of the bow apex can also be seen.

Earlier studies have hypothesized that the breaks in the NCFR were due to horizontal shearing instabilities of the alongfront wind (Hobbs and Persson 1982; Wakimoto and Bosart 2000; Carbone 1982; Braun et al. 1997). Linear wave theory (Haurwitz 1949) predicts that the fastest-growing mode is $\sim 7.5$ times the width of the shear zone across the leading edge of the front. To investigate this possibility, individual tail radar sweeps were examined during the along-frontal flight segment from 0520 to 0554 UTC (over 300 sweeps). To determine if this type of shearing instability might play a role in the behavior of this NCFR, the radial velocity for each tail radar sweep that went through the NCFR during the period the aircraft flew parallel to the line was examined to identify the transition at low-levels from receding to approaching radial velocity, indicating the shear zone at the leading edge of the NCFR. The average shear zone width was determined to be $\sim 2.97$ $\mathrm{km}$ with a standard deviation of $\sim 0.465 \mathrm{~km}$. A correction was applied to account for the fact that the beam did not intersect the NCFR perpendicularly, but rather at an angle $\sim 20^{\circ}$ from perpendicularity because of the fore/aft scanning technique. The range of shear zone width, 2.40-3.55 km implies, according to the linear wave theory, that the most unstable wavelength is $\sim 18.0-26.6 \mathrm{~km}$. This wavelength is a reasonable ap- 


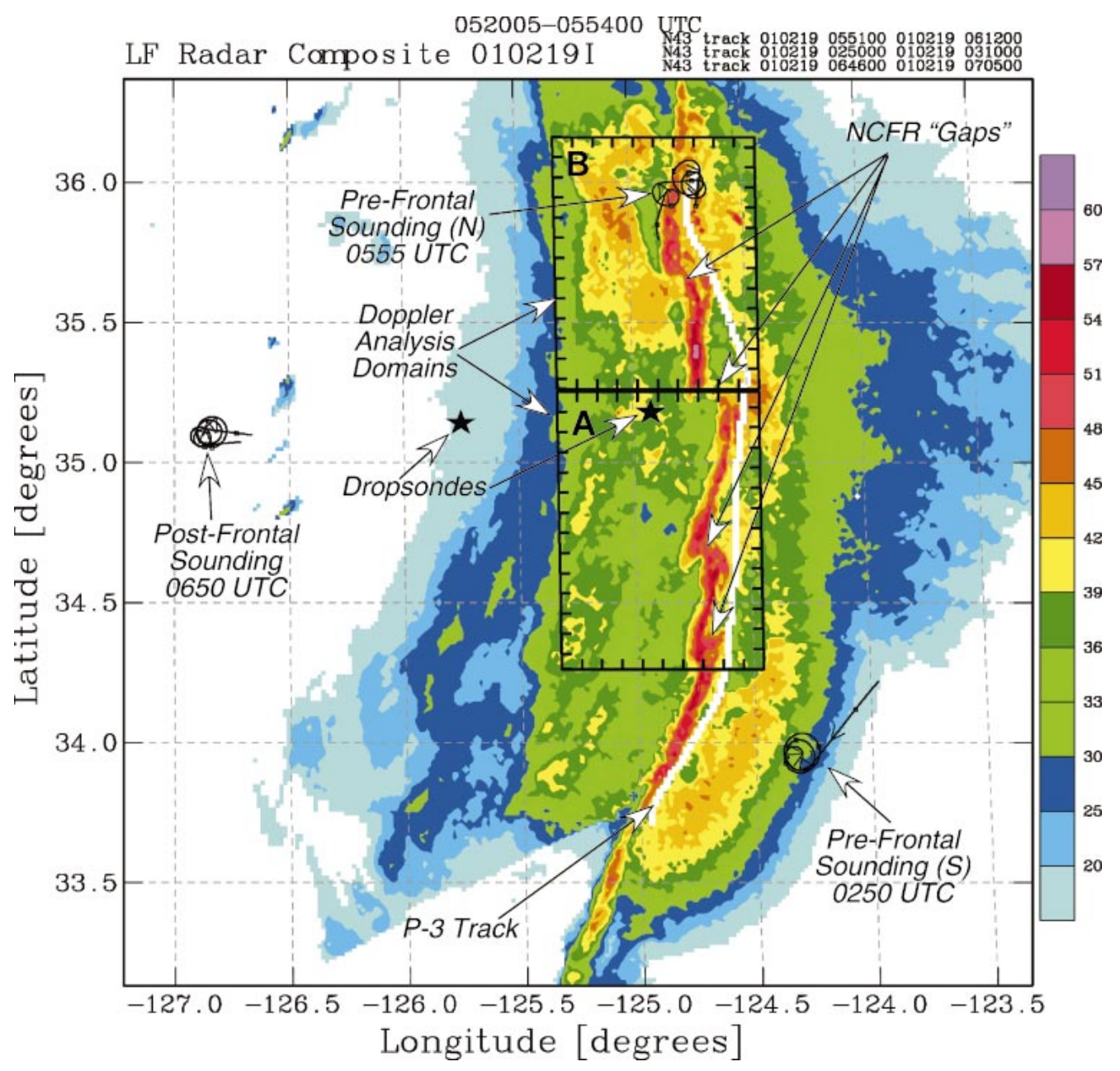

FIG. 6. Radar reflectivity composite of 68 scans from the P-3's lower fuselage radar from 0520 to 0554 UTC 19 Feb 2001. The P-3 track is indicated by the white line, the two psuedo-dual-Doppler analysis domains are marked by the two black boxes labeled A and $\mathrm{B}$, and the reflectivity color scale (dBZ) is at right. The locations of aircraft spiral ascents/descents are indicated by the spiral flight tracks with approximate time of descent or ascent. Dropsonde locations are marked with a black star. The P-3 tracks and dropsonde locations were time/space adjusted for the system motion $\left(053^{\circ}\right.$ at $\left.18 \mathrm{~m} \mathrm{~s}^{-1}\right)$ to the mean time of the radar composite (0537 UTC). The locations of four possible NCFR "gaps" are also noted.

proximation to the smaller gap distances revealed in the LF imagery in Fig. 6, providing evidence that shearing instability was perhaps a contributing mechanism responsible for part of the gap structure in this NCFR.

The vertical cross-line structure is shown in a pair of east-west vertical cross sections (Fig. 14) on either side of a gap or break in the NCFR (located at about $y=$ $50 \mathrm{~km}$ in Fig. 10) taken normal to the orientation of the NCFR. In both cross sections, low-level convergence was generated by the south-southeasterly flow ahead of the NCFR with postfrontal westerly flow behind it. This low-level convergence supported strong updrafts in the NCFR convective cores. The echo tops were only 4$4.5 \mathrm{~km}$ MSL in height, about one-third of the height of typical midwest U.S. convective storms (Burgess and Lemon 1990). Because of the relative shallowness of this NCFR, coastal National Weather Service (NWS) radars tend to not depict it well (not shown here) due to beam overshooting at long ranges because of the lowest elevation angles $\left(0.5^{\circ}\right.$ typically) and the terrain height of the radar stations along the coastal mountain range. The cross sections show updraft speeds along the leading edge to be $\sim 5-10 \mathrm{~m} \mathrm{~s}^{-1}$. These relatively strong updrafts result in overshooting tops. Below about 1.8 $\mathrm{km}$ MSL a strong rear to front current characterizes the postfrontal airflow. A strong cross-frontal temperature discontinuity is indicated by the descent in the brightband height from around $1.8 \mathrm{~km}$ MSL to the east of the NCFR to about $1 \mathrm{~km}$ MSL behind it. A stronger front to rear flow in the northernmost cross section A-A' (Fig. 14a) is clearly shown to the rear of the updraft in the 2-4-km layer. In the same cross section the low-level convergence is located very near the eastern edge of the high-reflectivity region. The precipitation core along 


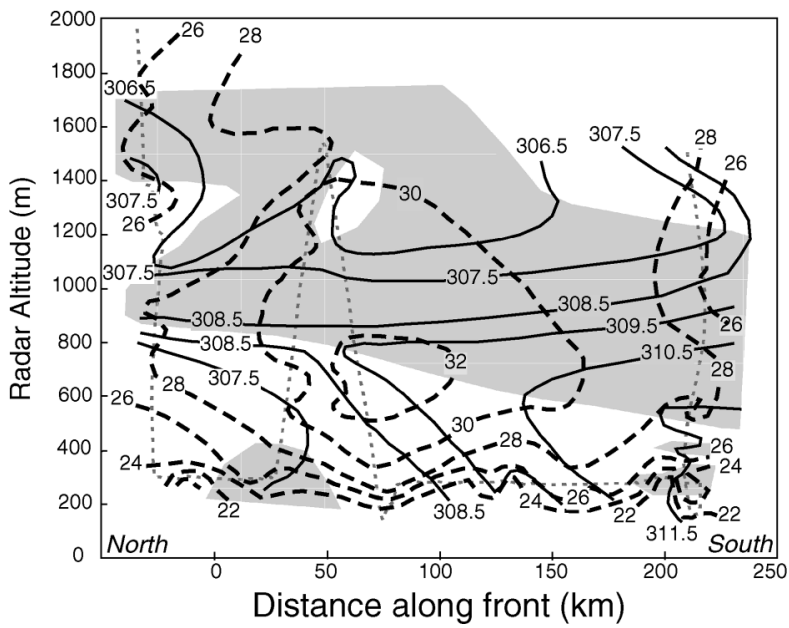

FIG. 7. Vertical cross section of wind speed (dashed red line; $\mathrm{m}$ $\left.\mathrm{s}^{-1}\right)$, equivalent potential temperature $\left(\theta_{e}\right.$; solid line; $\left.\mathrm{K}\right)$ based on aircraft in situ data collected during its traverse from south to north a few kilometers ahead of the NCFR (Fig. 6). The area of potential instability $\left(\partial \theta_{e} / \partial z<0\right)$ is shaded gray and the aircraft's track is depicted as the dotted line.

with the principal updraft is primarily vertically oriented below about $1.8 \mathrm{~km}$ and slopes slightly rearward above that level. In contrast, in the cross section south of the gap and through the bow apex (B-B', Fig. 14b) the strongest near-surface convergence is near the western, or rearward, edge of the high-reflectivity core, with an indication of a forward-leaning precipitation core. This downshear sloping updraft potentially leads to rain falling into the inflow air prior to that air rising in the updraft. A decrease in instability could then result from evaporative cooling leading to a weakening of convection. The composite sounding depicted in Fig. 5 as well as dropsondes in the NCFR rear (not shown) suggest midlevel dry air, which could be conducive to evaporative cooling.

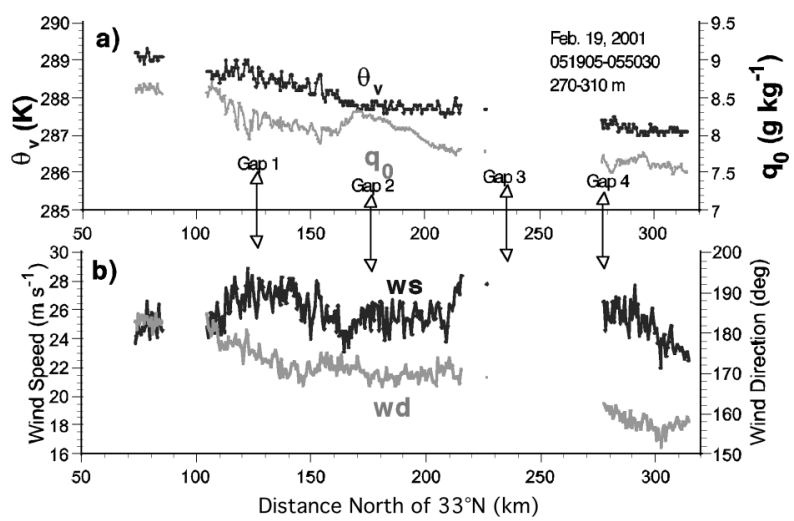

FIG. 8. In situ data from the P-3 aircraft for altitudes between 270 and $310 \mathrm{~m}$ during its alongfront transect in front of the NCFR between 0519:05 and 0550:30 UTC 19 Feb 2001. Shown are (a) virtual potential temperature $\left(\theta_{v}\right)$ and mixing ratio $\left(q_{\mathrm{o}}\right)$, and (b) wind speed (ws) and wind direction (wd). Also shown are the locations of the NCFR gaps marked in Fig. 6.
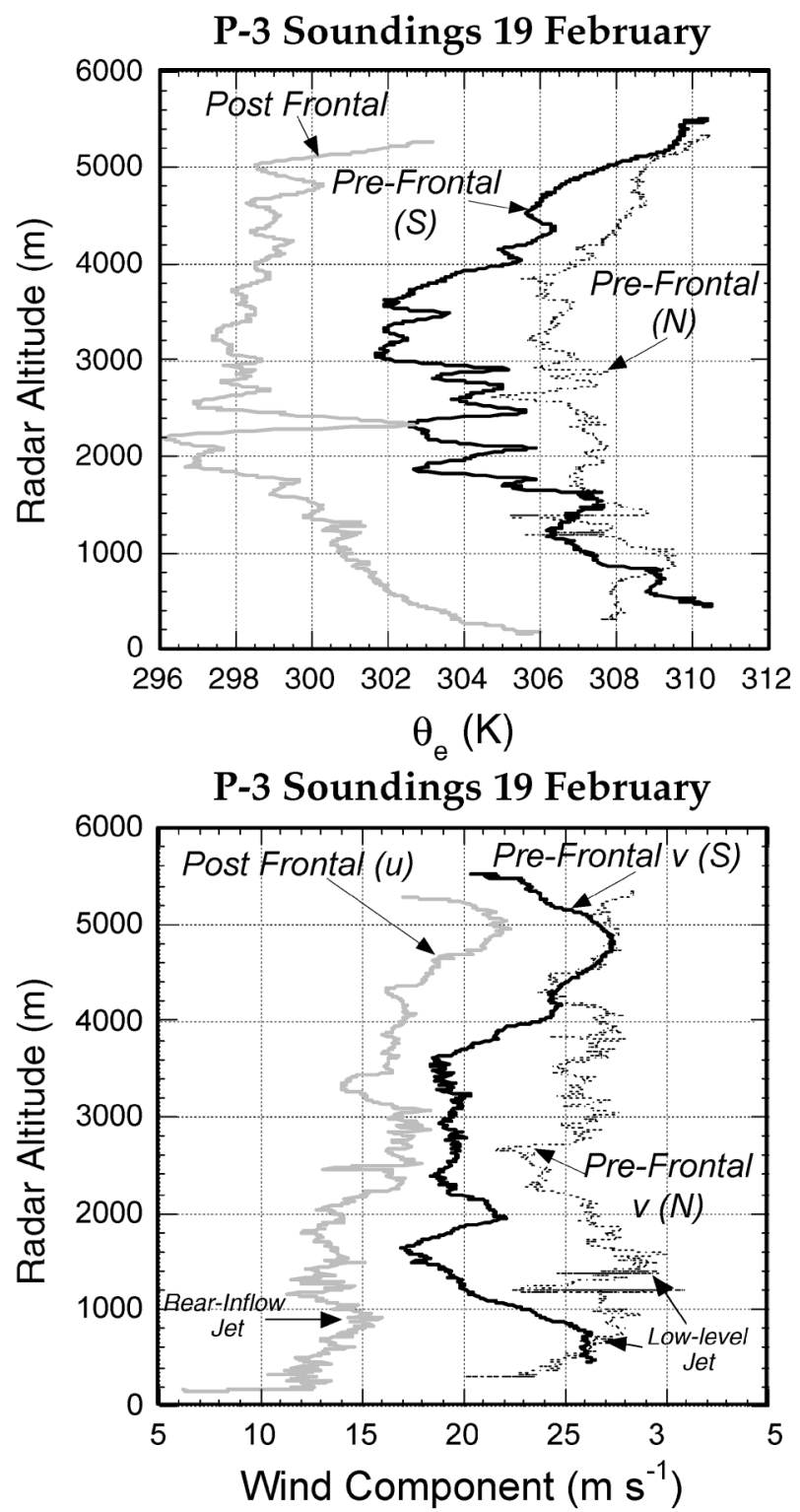

FIG. 9. (top) Equivalent potential temperature (K) profiles from the three P-3 ascent/descent soundings, the locations of which are shown in Fig. 6. The $u$ (east-west) component is shown for the postfrontal sounding; the $v$ (north-south) component is shown for the prefrontal soundings. (bottom) Wind components from the same three soundings $\left(\mathrm{m} \mathrm{s}^{-1}\right)$ from the same three displays.

\section{e. Air trajectories within leading-edge cores}

Locatelli et al. (1995) and Wakimoto and Bosart (2000) showed that precipitation cores of their NCFR's were not characterized by updraft along their entire length, but rather existed as cells displaced from the precipitation maxima. Their observations suggest that hydrometeors first form in the southern section of the cores and are advected by the low- and midlevel winds before falling as rain in the precipitation zone, which can appear elliptical and oriented at an angle to the cold front. The final shape and orientation of the precipitation 


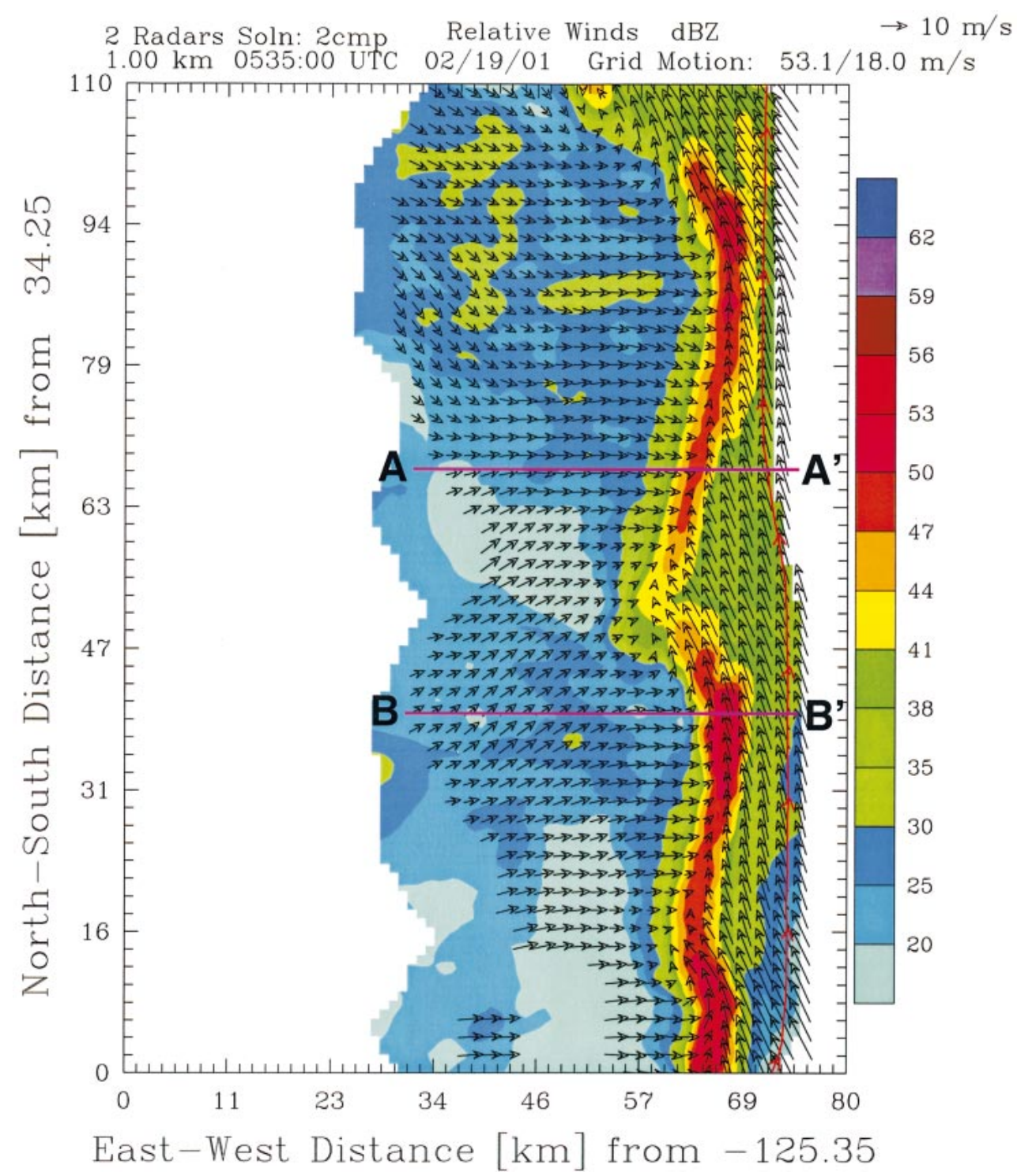

FIG. 10. Horizontal storm-relative winds and reflectivity field at $1.0 \mathrm{~km}$ MSL from the airborne pseudo-dualDoppler analysis for the region labeled A in Fig. 6. The P-3 flight track is shown as the thin red line running approximately south to north near the right-hand side. The shaded lines running approximately east-west and labeled $\mathrm{A}-\mathrm{A}^{\prime}$ and $\mathrm{B}-\mathrm{B}^{\prime}$ indicate the locations of vertical cross sections. The radar reflectivity color scale is shown at right and the wind scale at the top. The grid was moved with the mean line motion, toward $053^{\circ}$ at $18 \mathrm{~m} \mathrm{~s}^{-1}$.

cores relative to the cold front are therefore determined by the core-relative winds. To test this hypothesis on this NCFR, steady-state trajectories of air parcels that originate within the updraft zone of a pronounced bow in the NCFR were calculated using the Doppler-derived wind field to approximate the path of the hydrometeors carried by the core-relative winds.

The results of the steady-state trajectory calculation are shown in Fig. 15. The parcels were released at the lowest grid level along a north-south line (black dots) within the updraft zone. Trajectories were calculated backwards $1 \mathrm{~h}$ from the release point to as much as 1 $\mathrm{h}$ forward in time or until the parcel exited the echo through the back edge or top. The trajectories all show a northwestward path although the ones near the northern edge of the pronounced bow near $y=40 \mathrm{~km}$ exhibit a more upright structure than the parcels south of the bow or within the break region north of the bow. Thus, these calculations support the conclusions in Wakimoto and Bosart (2000).

\section{f. Vertical circulations at the leading edge of the NCFR}

The different structural nature of the NCFR revealed in the two cross sections in Fig. 14 indicates that dif- 


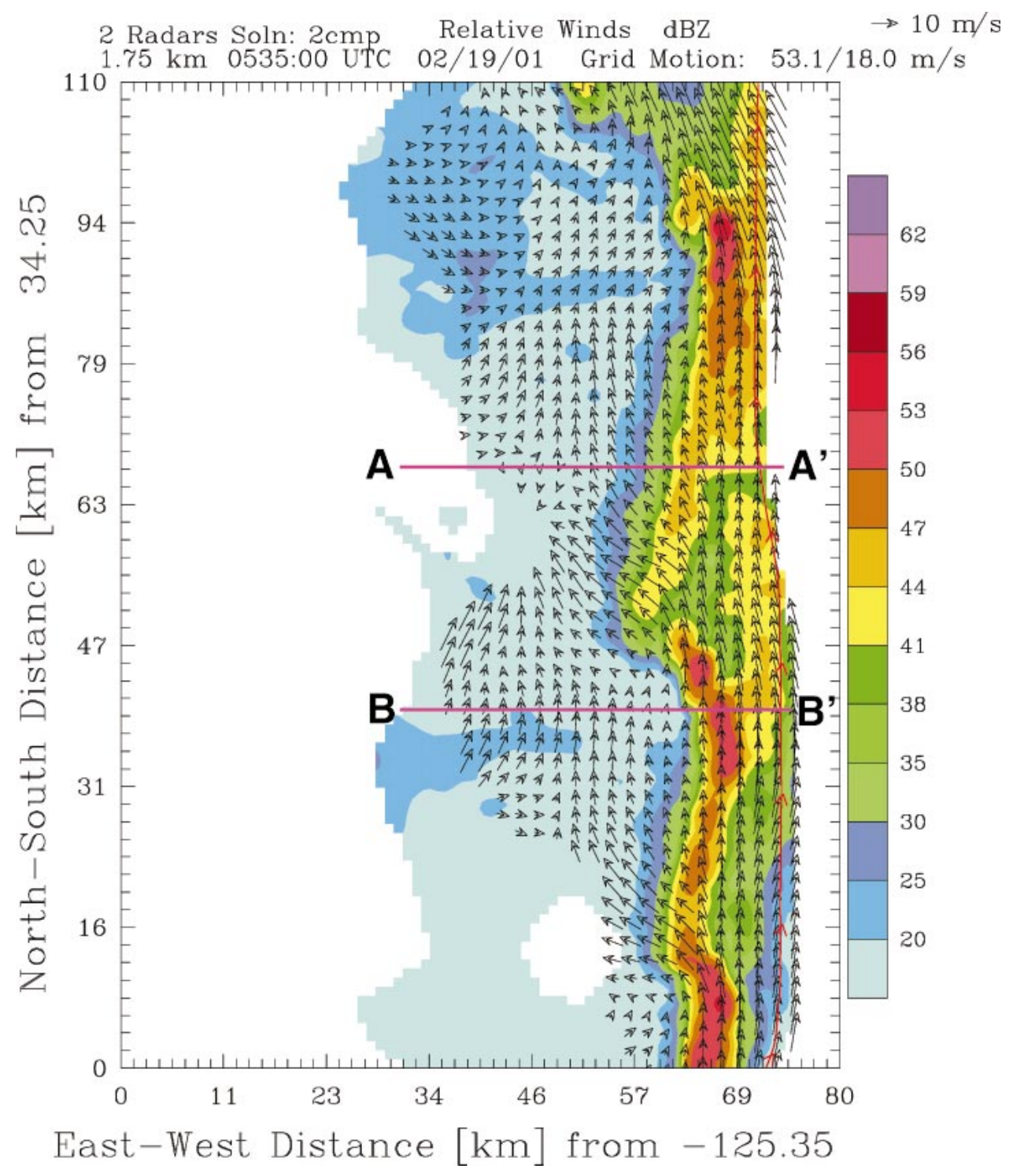

FIG. 11. As in Fig. 10 except for 1.75 km MSL.

ferent physical processes are acting on the NCFR at locations on either side of the gap. Many previous studies have stressed the importance of gravity-current dynamics, particularly frictional processes within the boundary layer, to the character of the lifting along the leading edge of the surface front (Chen et al. 1997). Radial velocity and reflectivity fields derived from individual scans of the P-3s' tail Doppler radar clearly show gravity-current-like structure (not shown) in this NCFR along most of its 200-km length (Fig. 6). Other examples of radar scans through NCFR leading edges can be found in Wakimoto and Bosart (2000). Parsons (1992) showed that low-level front-normal ambient wind shear determines the character of the lifting at the cold air leading edge. Using a series of numerical experiments with a two-dimensional version of the Klemp and Wilhelmson (1978) cloud model, he demonstrated that an "optimal" vertical shear balance between the environmental shear and shear induced by the advancing cold air exists where the frontal updraft is upright and sustained. Rotunno et al. (1988) offer a complementary viewpoint of this process involving horizontal vorticity balance between the low-level environmental wind shear and the vorticity produced by the cold air (RKW theory). A sustained, erect updraft is produced when the horizontal vorticity produced at the leading edge of the cold air is balanced by the vorticity contained in the ambient shear. Weisman (1993) extended the Rotunno et al. (1988) ideas to bow-echo systems that contained strong rear inflow using a series of numerical simulations. Although the cold air described by Rottunno et al. (1988) is maintained by evaporative cooling and 


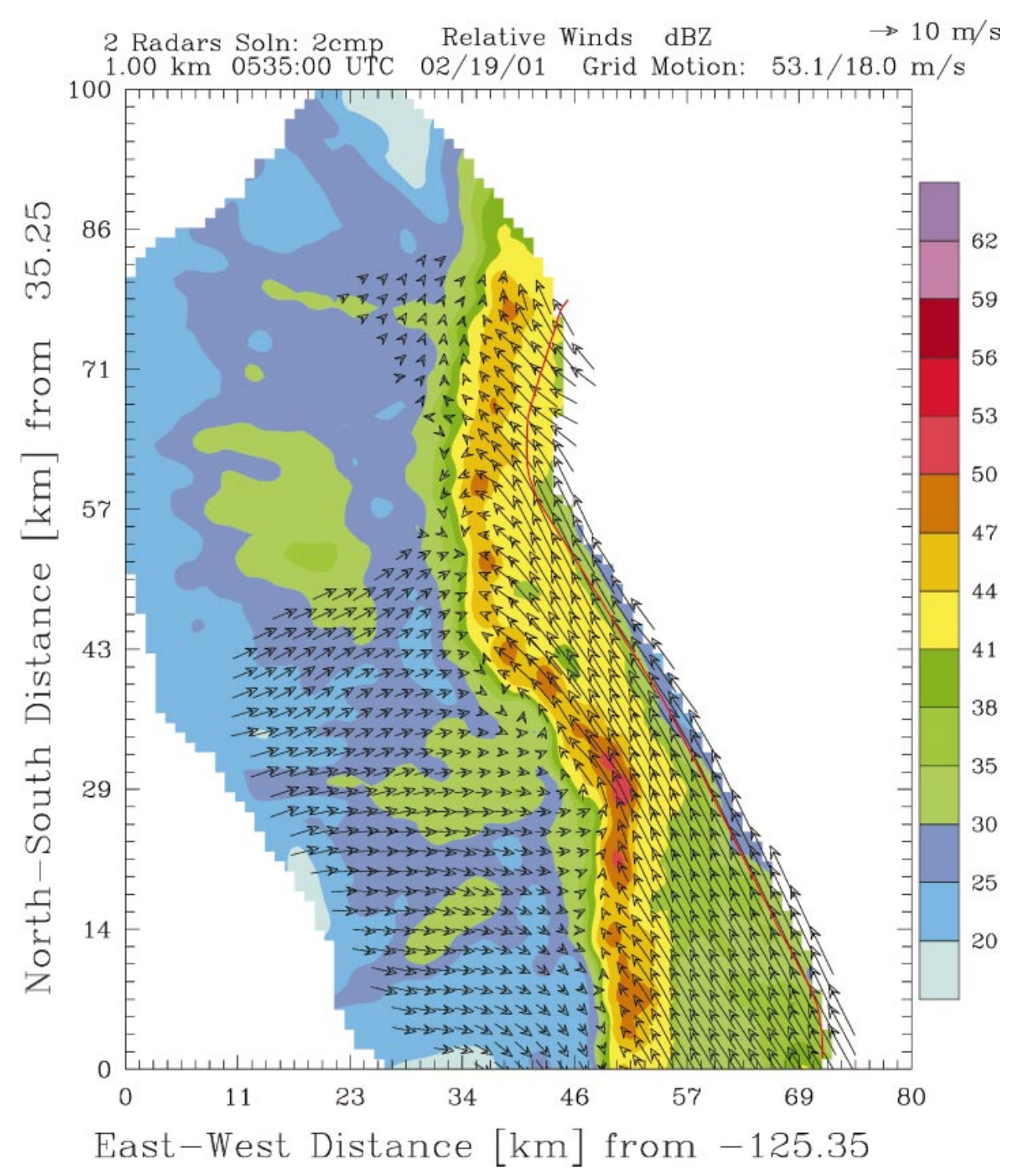

FIG. 12. As in Fig. 10 except for the pseudo-dual-Doppler analysis for the region labeled B in Fig. 6.

downdrafts within the heavy rain region of the squall line, here, the cold air refers to the advancing low-level cold air behind the NCFR, which is probably maintained by large-scale advection of cold air plus evaporative cooling processes within the heavy rain region of the NCFR.

In a two-dimensional framework (Fig. 16) the tilt of the principal updraft of a convective system is proposed to be downshear (Fig. 16a) if the cold-air-generated vorticity is less than the ambient environmental shear, upright (Fig. 16b) if the two opposing shears are roughly in balance, and upshear (Fig. 16c) if the cold-air-generated vorticity dominates the environmental shear. Weisman (1993) termed the sequence as "evolutionary" since the strengthening and deepening of the cold air takes place over a finite time and in his simulations the bow echo evolved into a mature system once the cold air matured. Once the system tilts upshear, a rear inflow is generated in response to the establishment of a mesolow just behind the leading edge at low levels (Jorgensen et al. 1997). The mesolow is generated hydrostatically as a result of warm buoyant air being lifted over the cold air. Such a strong upshear tilt would not lead to intense precipitation along a narrow zone near the surface frontal position, but a broad zone of precipitation extending to the rear of the system (Parsons 1992).

Parsons (1992) treated the NCFR as a two-dimensional entity. Clearly, the NCFR discussed here is not two-dimensional. However, it is hypothesized that the same RKW theory can be applied to NCFR structure that involves breaks and gaps in the line if the vorticity balance is applied to individual local bow-shaped elements. Brown et al. (1999) argue that density-current theory should only apply in local regions of the cold 


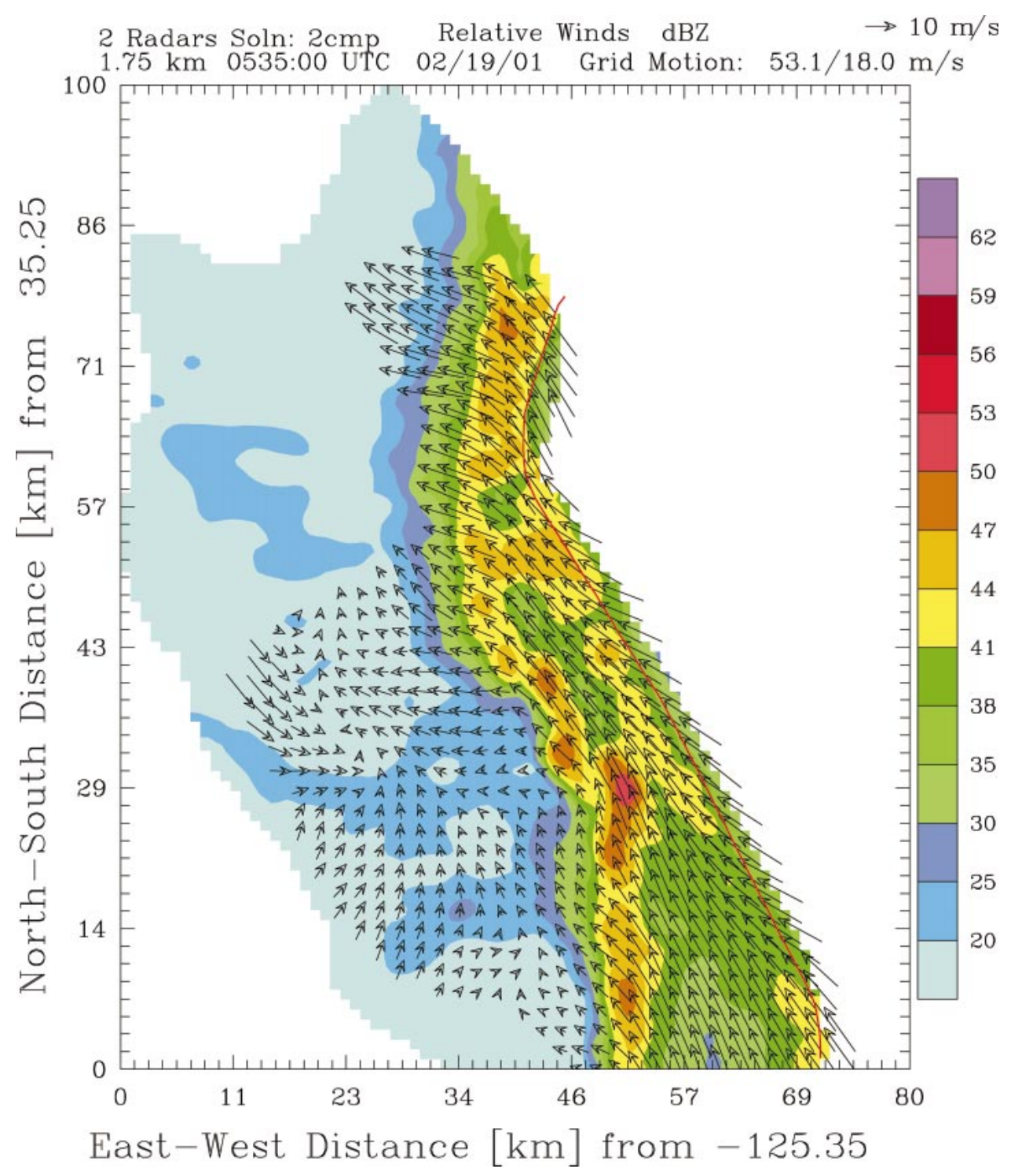

FIG. 13. As in Fig. 12 except for the $1.75 \mathrm{~km}$ MSL.

front, especially near precipitation cores. Wakimoto and Bosart (2000) found that their NCFR density-current arguments could not explain the observed motion of the overall front, but did describe the motion of precipitation core segments of the NCFR. To evaluate whether gravity-current theory can be used to approximate this front's overall motion, the expression for propagation speed of a density current is evaluated. The formula used here includes a term representing the retardation of motion by opposing prefrontal flow (Simpson and Britter 1980):

$$
c=k \sqrt{g h \frac{\Delta \bar{\theta}_{v}}{\bar{\theta}_{v c}}}+b u_{0},
$$

where $c$ is the frontal propagation speed, $g$ the gravitational acceleration, $h$ is the depth of the cold air, $u_{0}$ is the prefrontal cross-front wind component (negative for air motion toward the front), $\Delta \bar{\theta}_{v}$ the mean difference in virtual potential temperature across the front, $\bar{\theta}_{v c}$ the mean virtual potential temperature in the cold air, $k$ the internal Froude number (0.7-1.1; Koch 1984), and $b$ is constant (0.6).

The calculation of $c$ is based on a dropsonde about $50 \mathrm{~km}$ to the west of the NCFR leading edge (depicted on Fig. 6 as the star closest to the leading edge). From this sounding $\Delta \bar{\theta}_{v}=2.1 \mathrm{~K}, \bar{\theta}_{v c}=287.4 \mathrm{~K}$, and $h=$ $2.1 \mathrm{~km}$. The value of $u_{0}$ was determined to be roughly $+7.1 \mathrm{~m} \mathrm{~s}^{-1}$, based on averaging the Doppler winds over a $3-\mathrm{km}$ east-west by $15-\mathrm{km}$ north-south region ahead of the front, centered on the apex of the pronounced reflectivity bow at $y=37$ in Fig. 10, and over the cold air depth assuming the front to be north-south oriented. 

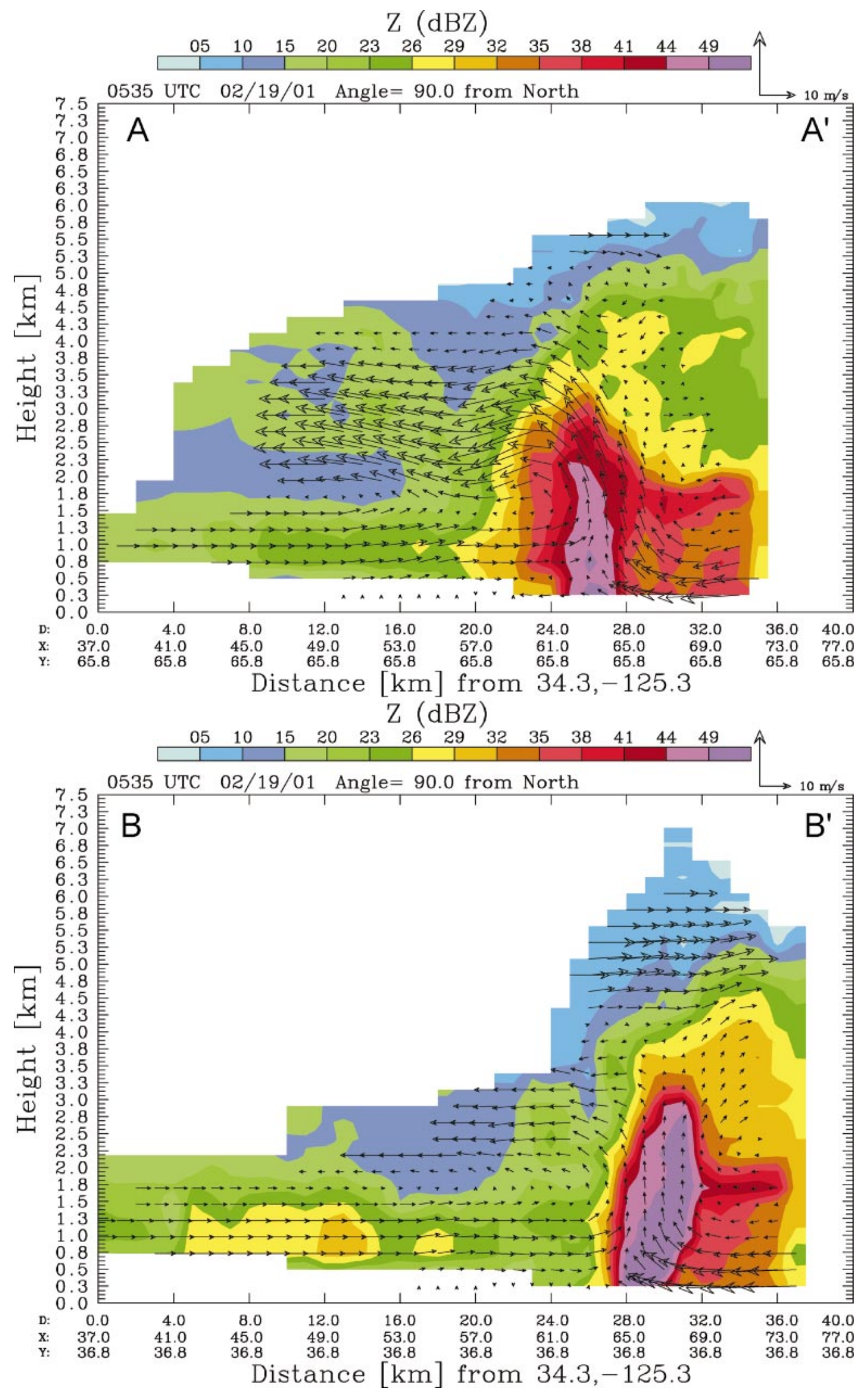


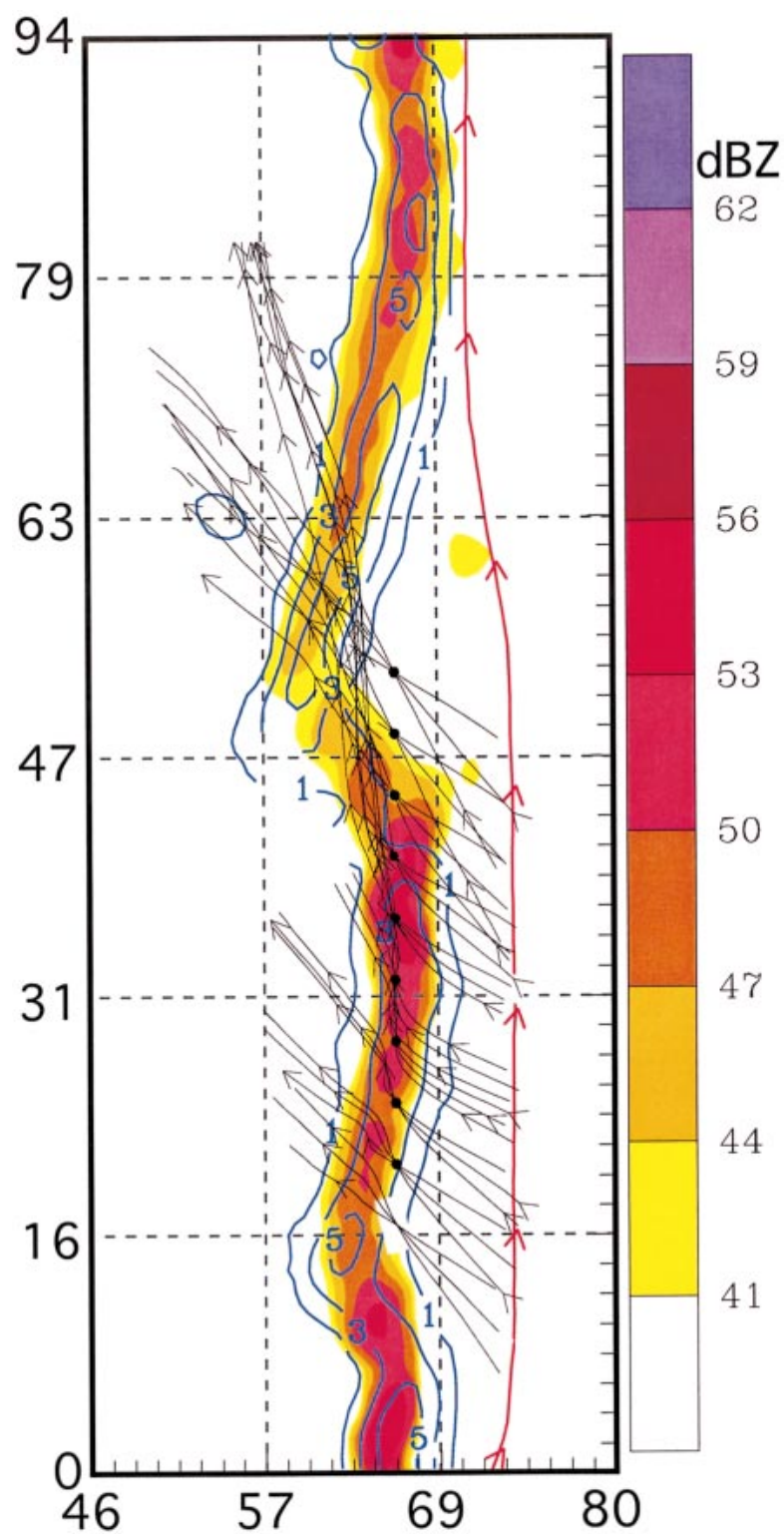

FIG. 15. Air parcel trajectories (black lines with arrow heads) released in the updraft zone near the precipitation core near $y=31$ $\mathrm{km}$. Black dots represent the locations of release with the trajectory calculation going backward $30 \mathrm{~min}$ and forward up to 60 min unless terminated by exiting the domain or cloud top. The $1-\mathrm{km}$ reflectivity field is shown with the color scale to the right. Vertical velocity $\left(\mathrm{m} \mathrm{s}^{-1}\right)$ at $1 \mathrm{~km}$ is shown as the blue solid contours. The P-3 flight track is shown as the red line with arrows.

\section{EVOLUTIONARY STAGES}

(a)

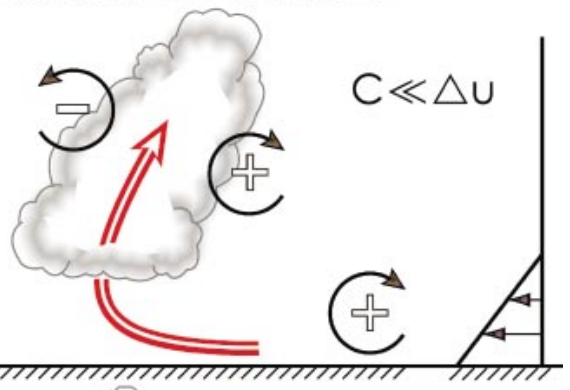

(b)

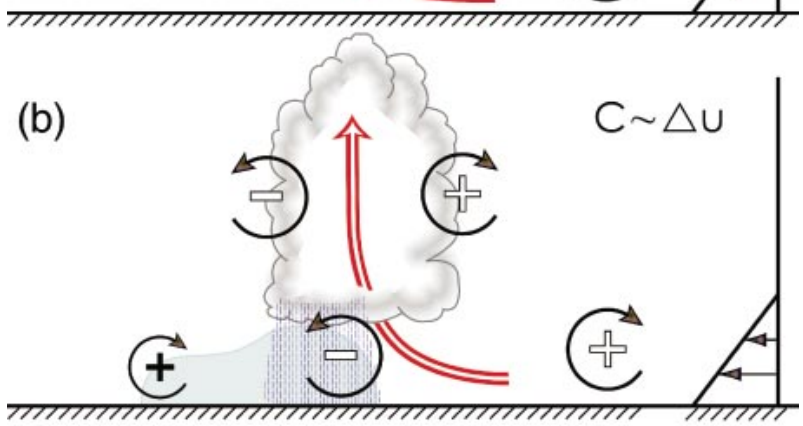

(c)

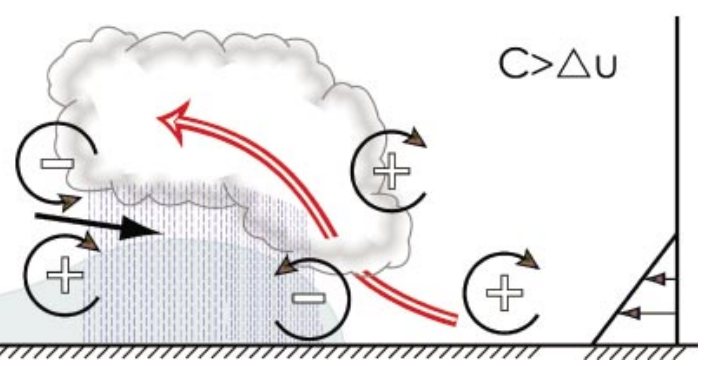

FIG. 16. Schematic diagram showing the various responses of a convective updraft to various strengths of the environmental lowlevel wind shear and cold air. The sense of the circulations (i.e., horizontal vorticity) associated with the environmental wind shear $(\Delta u)$, illustrated by the profile with arrows on the right, and cold air $(C)$ are depicted by circular arrows. Here, $C$ is approximated by the difference in velocity at the top and bottom of the cold air. The red arrow denotes the updraft current. Blue shading denotes the cold air. Rainfall regions are indicated by light vertical lines with the outline of the cloud indicated by the shaded, scalloped lines. [From Weisman (1993).]

Using Eq. (1) the frontal speed was computed to be $\sim 12.8-17.8 \mathrm{~m} \mathrm{~s}^{-1}$, depending on the range of the Froude number. Values of these parameters extracted from the aircraft's descent sounding about $200 \mathrm{~km}$ to the west of the NCFR (shown in Fig. 6 as the spiral flight track) yield nearly the same value for $c$. The observed east-west speed of the overall front derived from reflectivity isochrones was $14.4 \mathrm{~m} \mathrm{~s}^{-1}$, thus the gravitycurrent velocity did reasonably approximate the front's

FIG. 14. Vertical cross section of radar reflectivity and system-relative winds in the plane of the cross section for the sections labeled (top) $\mathrm{A}-\mathrm{A}^{\prime}$ and (bottom) $\mathrm{B}-\mathrm{B}^{\prime}$ in Fig. 10. The vertical wind scale has been stretched to match the plot aspect ratio. Reflectivity color scale and wind scale are at the top of each figure. 
overall observed motion, in contrast with the results of Wakimoto and Bosart (2000). In their study the motion of reflectivity cores did reasonably approximate densitycurrent theory (because $u_{0}$ increased due to the precipitation core being oriented at an angle of about $20^{\circ}$ to the average front location). The precipitation cores of this NCFR could not be made to conform to densitycurrent theory.

In a manner similar to the density-current evaluation, the balance of vorticity argument presented by RKW can be evaluated by comparing the horizontal vorticity in the ambient flow with that induced by the density changes across the leading edge of the cold air (the parameter $C$ in Fig. 16). That parameter can be approximated by the forward speed of the density current, $c_{\mathrm{dc}}$ :

$$
c_{\mathrm{dc}}=\sqrt{g h \frac{\Delta \bar{\theta}_{v}}{\bar{\theta}_{v c}}} .
$$

Evaluating Eq. (2) using the postfrontal sounding data results in $c_{\mathrm{dc}} \sim 12.2 \mathrm{~m} \mathrm{~s}^{-1}$. The prefrontal ambient shear-induced vorticity can be represented by $\Delta u$, which is the vertical shear over the depth of the cold air $(h)$ and can be readily estimated from the pseudo-dualDoppler-derived winds. Two mean profiles of crossfrontal winds are shown in Fig. 17, derived by horizontally averaging the Doppler winds over a $5 \mathrm{~km}$ by $10 \mathrm{~km}$ box ahead of the NCFR centered on the eastern end point of the two cross sections $A-A^{\prime}$ and $B-B^{\prime}$ (locations shown in Fig. 14). The plot shows stronger low-level prefrontal shear (i.e., $\Delta u$ over the lowest 2.1 $\mathrm{km})$ for the profile $\mathrm{B}-\mathrm{B}^{\prime}$ south of the gap $(\Delta u \sim 15 \mathrm{~m}$ $\left.\mathrm{s}^{-1}\right)$, than the profile near $\mathrm{A}-\mathrm{A}^{\prime}$ north of the gap $(\sim 4$ $\mathrm{m} \mathrm{s}^{-1}$ ). The prefrontal $\Delta u$ south of the gap is slightly larger than the horizontal vorticity shear due to the cold air computed by Eq. (2). Rotunno et al. (1988) hypothesized that this inequality would lead to a condition in which convection at the leading edge of the cold air is tilted downshear (Fig. 16a). Conditions north of the gap are such that $c_{\mathrm{dc}}>\Delta u$, and RKW theory would predict an upshear-tilted updraft with a broader rainfall maximum. Figure 14 shows that the updraft is tilted upshear with a broader rainfall maxima along $\mathrm{A}-\mathrm{A}^{\prime}$ and slightly downshear along $\mathrm{B}-\mathrm{B}^{\prime}$, in agreement with the ideas of RKW.

To examine the character of the updraft flow around other gaps in the NCFR many cross sections were examined. A summary of the survey is shown in Fig. 18, which shows the relationship of the updraft core locations to the rainfall maxima and $0.5 \mathrm{~km}$ AGL relative wind. The regions where the updraft cores, very nearly coincident with the near-surface convergence maxima, coincided with maximum reflectivity are labeled erect to match with the vertically erect nature of the reflectivity core in the cross sections. Similarly, where the updraft core is east (west) of the reflectivity maximum

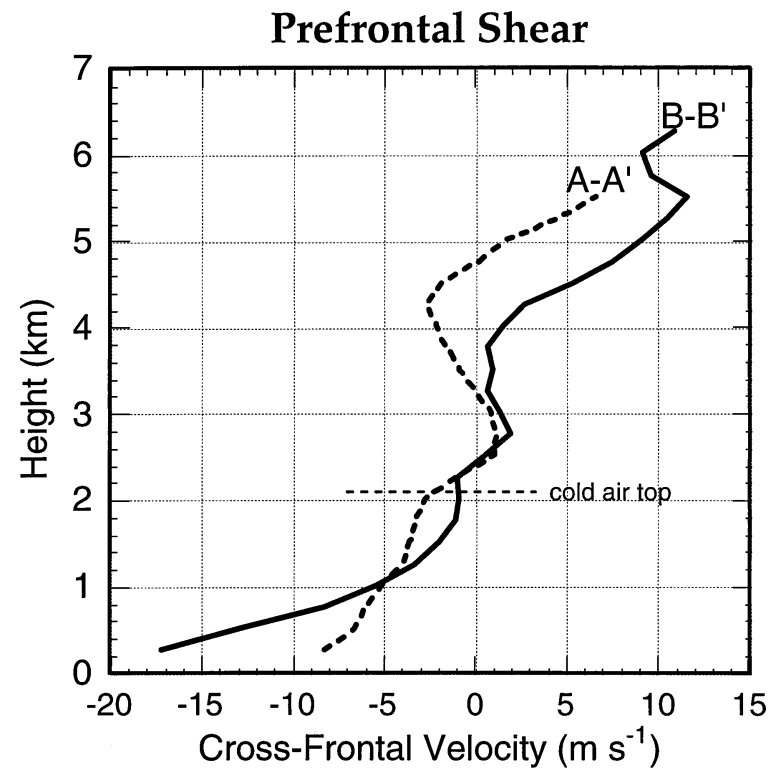

FIG. 17. Vertical profiles of mean cross section cross-frontal wind velocity within the regions ahead of the surface frontal position derived from pseudo-dual-Doppler observations. The line labeled A$\mathrm{A}^{\prime}$ represents conditions near the part of the NCFR just north of the break shown in Fig. 10 near $y=50 \mathrm{~km}$, while the line labeled B$\mathrm{B}^{\prime}$ represents conditions to the south of the gap region. The averaging domains are $5 \mathrm{~km}$ (east-west) by $10 \mathrm{~km}$ (north-south) boxes ahead of the NCFR that are centered on the eastern end point of the two cross sections $\mathrm{A}-\mathrm{A}^{\prime}$ and $\mathrm{B}-\mathrm{B}^{\prime}$.

the region is labeled upshear (downshear), respectively. The repeatable, systematic nature of the relationship of updraft tilt to its location along the NCFR is seen. Regions just south of a gap region and near or slightly north of the apex bow high-reflectivity cores are characterized by downshear-tilted updrafts, transitioning to the south to erect updrafts and finally to upshear-tilted updrafts at the southern end of the precipitation cores just north of the next gap region.

Other factors possibly limit the application of RKW theory to NCFRs. Spatial and temporal variations of cold air strength and depth owing to diabatic cooling in the cold air resulting from localized hydrometeor evaporation and melting are complicating factors. Local boundary layer modification of the cold air due to airsea fluxes and consequent generation of horizontal vorticity by horizontal buoyancy gradients not associated with the leading edge of the cold air (Lafore and Moncrieff 1989) also represent possible limitations. Nonetheless, the coevolving fields of wind and NCFR precipitation structure are highly suggestive of the relevance of RKW theory in explaining these NCFR structures. Some factors that limit the application of RKW theory to deep convective lines have less of a concern here. For example, although Weisman (1993) found that certain squall-line environments contained sources of vorticity, other than the balance at the leading edge, that need to be considered when assessing the behavior of 


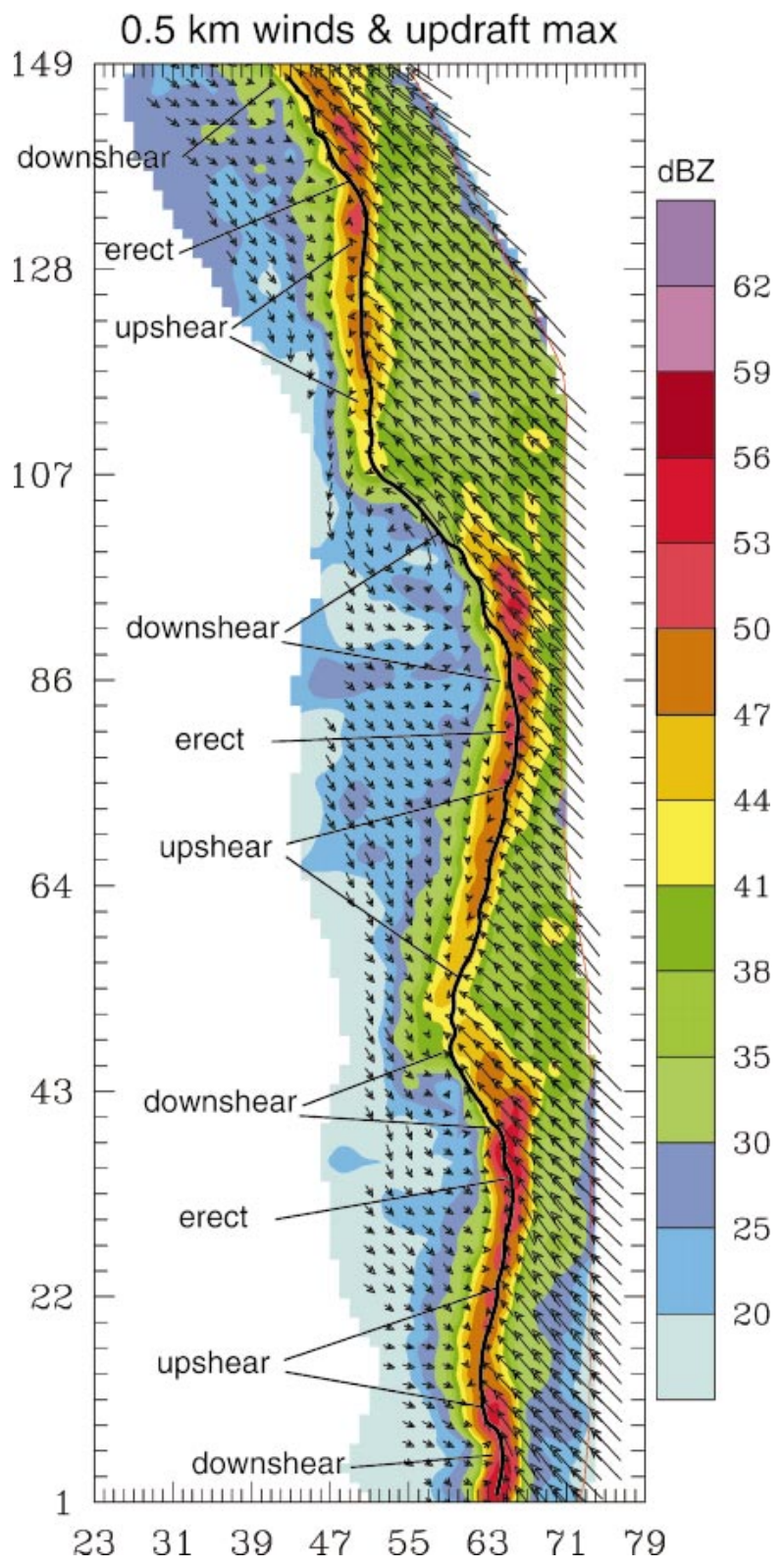

FIG. 18. Horizontal storm-relative winds and reflectivity field at $0.5 \mathrm{~km}$ MSL from the airborne pseudo-dual-Doppler analysis for both regions labeled A and B in Fig. 6. The P-3 flight track is shown as the thin red line running approximately south to north near the righthand side. The heavy black line connects the ribbon of maximum vertical velocity. Regions where the updraft is to the west of the rainfall maxima are designated downshear zones, regions where updraft and reflectivity cores are coincident are labeled erect, and regions where updrafts are to the east of reflectivity cores are labeled upshear. leading-edge updrafts, in our NCFR case the limited potential instability and small buoyancy gradients limit those concerns. Yu and Smull (2000) performed similar calculations of vorticity balance using buoy and airborne Doppler observations for an NCFR approaching the northern California coast and found that, in the mean, density-current theory did adequately describe the motion of that NCFR. Moreover, the vertical shear in advance of the front was generally "suboptimal" (i.e., $C$ $\gg \Delta u$ ) until just before landfall consistent with vertical cross sections that showed frontal updrafts sloping over the cold air and upshear tilt. They also noted a progression toward more erect updrafts and narrower rainfall patterns as the NCFR moved closer to the coast, coincident with increases in prefrontal low-level shear. They concluded that low-level upstream blocking was an important factor in changing the character of the frontal updraft as the front made landfall. This effect would not apply in the farther offshore case described here.

\section{Numerical model simulations}

To augment the in situ observations of cold air strength and depth in the cold air across the NCFR gap regions, mesoscale numerical model simulations are used to assess the role of vorticity balance at the NCFRs leading edge in defining the character of the frontal updrafts.

\section{a. Model description}

The nonhydrostatic version of the Penn State-NCAR MM5 (Dudhia 1993; Grell et al. 1995) was used to conduct numerical simulations of the NCFR. A twoway interactive, four-level nested grid technique was employed to achieve the multiscale simulation. Table 2 provides specifications for each nested domain. The outer domains A and B (grid spacing of 36 and $12 \mathrm{~km}$, respectively) were fixed and were designed to simulate the mesoscale environment in which the system evolved. The finer domains C and D (4- and 1.3-km grid spacing, respectively) were initialized at 6 and $13 \mathrm{~h}$, respectively, to simulate the more detailed NCFR structure. The model vertical structure was composed of 27 sigma levels with the top of the model set at a pressure of $50 \mathrm{hPa}$. The sigma levels were placed at values of 1.0, 0.99, $0.98,0.96,0.93,0.89$, and then decreased to 0.01 at intervals of 0.04 . The model initial conditions for the $36-$ and $12-\mathrm{km}$ grid was derived from the NOAA/NCEP

TABLE 2. MM5 model design.

\begin{tabular}{lcccc}
\hline \hline \multicolumn{1}{c}{ Domain } & Mesh A & Mesh B & Mesh C & Mesh D \\
\hline Dimensions & $150 \times 180$ & $277 \times 250$ & $301 \times 220$ & $301 \times 220$ \\
Grid size $(\mathrm{km})$ & 36 & 12 & 4 & 1.3 \\
Time step (s) & 90 & $0-18$ & $6-18$ & 3.3 \\
Integration hours & $0-18$ & & 10 & $13-18$ \\
\hline
\end{tabular}




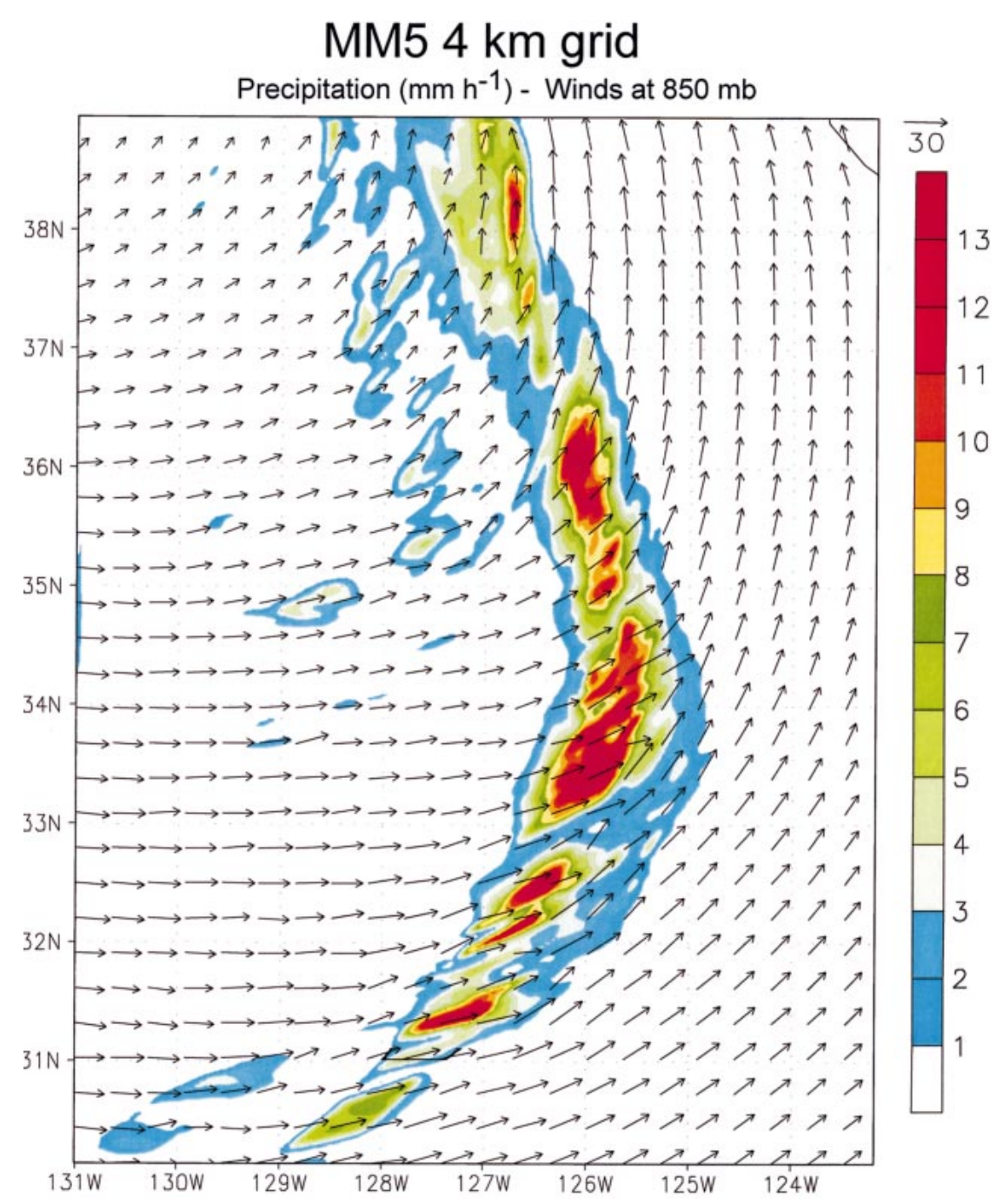

Fig. 19. Horizontal view of 4-km grid mesh earth relative flow and 1-h accumulated precipitation $(\mathrm{mm})$ at $850 \mathrm{hPa}$ valid at $0500 \mathrm{UTC} 19 \mathrm{Feb} 2001$ after $17 \mathrm{~h}$ of integration. Precipitation color scale is at right.

analyses archived at the National Center for Atmospheric Research. The simulation started at 1200 UTC 18 February 2001. The "valid time" for comparison to the P-3 observations was therefore 0600 UTC 19 February 2001. No ad hoc initialization using a traditional cold air or warm thermal bubble was used, rather the clouds generated in the simulations were the result of explicitly resolved mesoscale convergence fields. Physics options used in this study included the Kain-Fritsch cumulus parameterization, a simple ice microphysics scheme (Dudhia 1993), the Blackadar high-resolution planetary boundary layer parameterization scheme (Zhang and Anthes 1982), and a cloud atmospheric radiation scheme (Dudhia 1993). For the simulations, the model physical processes were the same for each domain except that no cumulus parameterization scheme was included for the 4- and 1.3-km domains.

\section{b. Model results}

A plan view of the $850-\mathrm{hPa}$ system relative flow and 1-h accumulated precipitation from the 4-km grid mesh of the model-simulated NCFR after $17 \mathrm{~h}$ are shown in Fig. 19. The model produced an arc-shaped rainband that was moving at $(u, v)=(12.8,15.4) \mathrm{m} \mathrm{s}^{-1}$ with the apex of the bow near $34.5^{\circ} \mathrm{N}$. Much like the observed NCFR, the modeled version was near the bottom of the large-scale trough, although the modeled NCFR is $\sim 1^{\circ}$ west of the observed NCFR. The accumulated precipitation for the 5-h time period from hours 13 to 18 of the forecast run (which corresponds to 0100-0600 UTC 19 February 2001) is shown in Fig. 20. During this 5$\mathrm{h}$ period, the simulated NCFR was bow-shaped and propagated rapidly eastward much like the observed motion of the NCFR. However, the simulated NCFR 


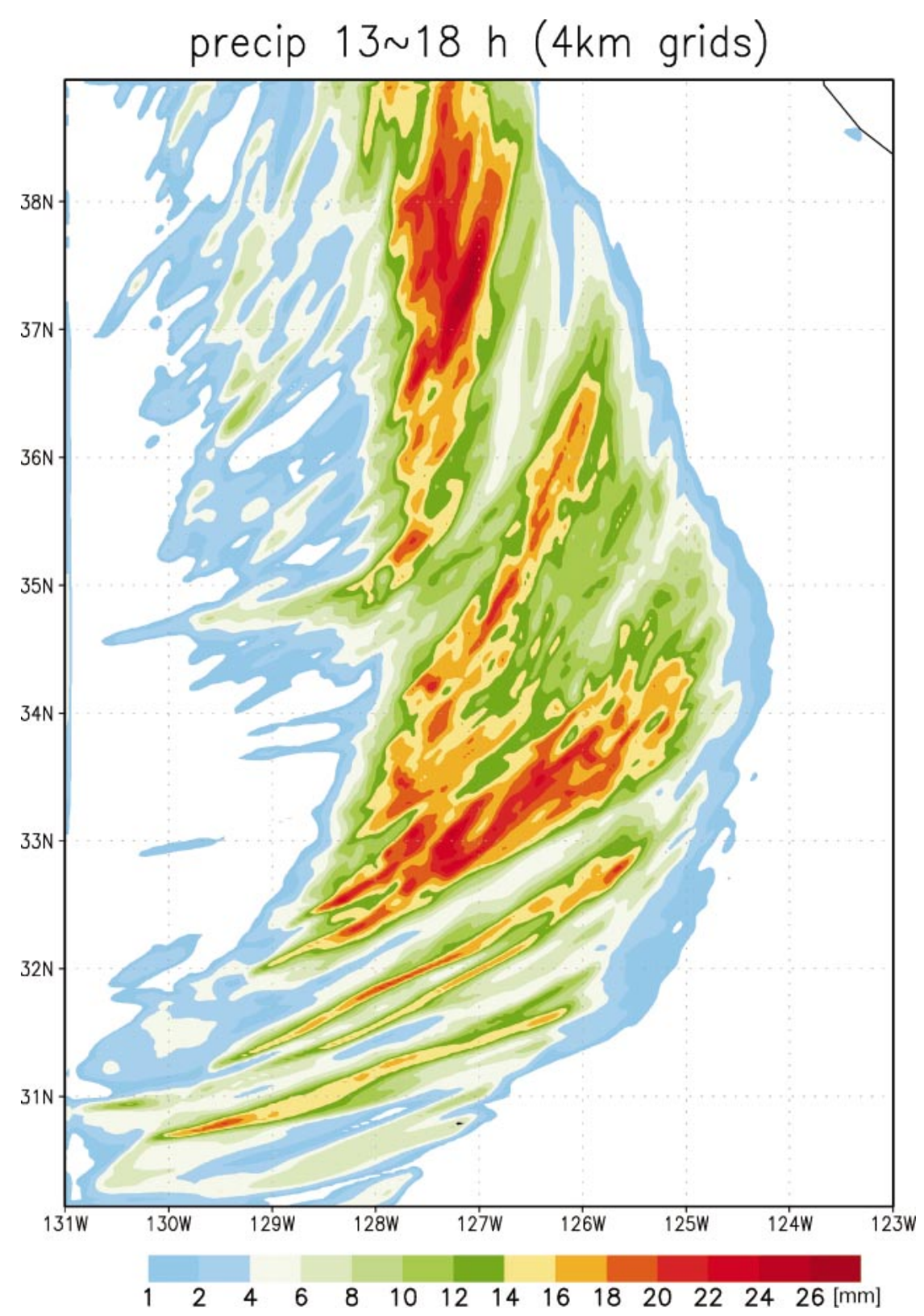

FIG. 20. Surface model precipitation $\left(\mathrm{mm} \mathrm{h}^{-1}\right)$ for the 5 -h period from 13 to $18 \mathrm{~h}$ after initialization (0100 to 0600 UTC 19 Feb 2001) from the 4-km grid.

was not positioned as the observed NCFR and the simulated motion was also different. Therefore, the simulated gaps and cores do not necessarily correspond to similar features in the observed NCFR, but rather correspond in a general sense.

Near the apex of the NCFR bow, its motion was reasonably similar to the observed NCFR motion from lower fuselage radar image sequence $(u, v)=(14.4,10.8)$ $\mathrm{m} \mathrm{s}^{-1}$. Much like the observed NCFR between $33^{\circ}-$ $36^{\circ} \mathrm{N}$ (Fig. 6), the simulated NCFR exhibited gaps, particularly near $35^{\circ} \mathrm{N}$, with precipitation cores moving as discrete elements. The motion of these cores was not uniform along the NCFR. North of about $36^{\circ} \mathrm{N}$ the cores moved mostly northerly, while south of about $32^{\circ} \mathrm{N}$ the core motion was east-northeasterly. This diverse motion was likely in response to the mid- and upper level-flow pivoting around the synoptic surface low shown in the satellite photograph near $39^{\circ} \mathrm{N}, 134^{\circ} \mathrm{W}$ at this time (Fig. 4).

The model-simulated NCFR structure around the gap region near $35^{\circ} \mathrm{N}$ is revealed in the surface precipitation and surface equivalent potential temperature $\left(\theta_{e}\right)$ analyses for 0600 UTC 19 February 2001 (Fig. 21). South of the gap region near $35^{\circ} \mathrm{N}$, the coldest surface $\theta_{e}$ was 


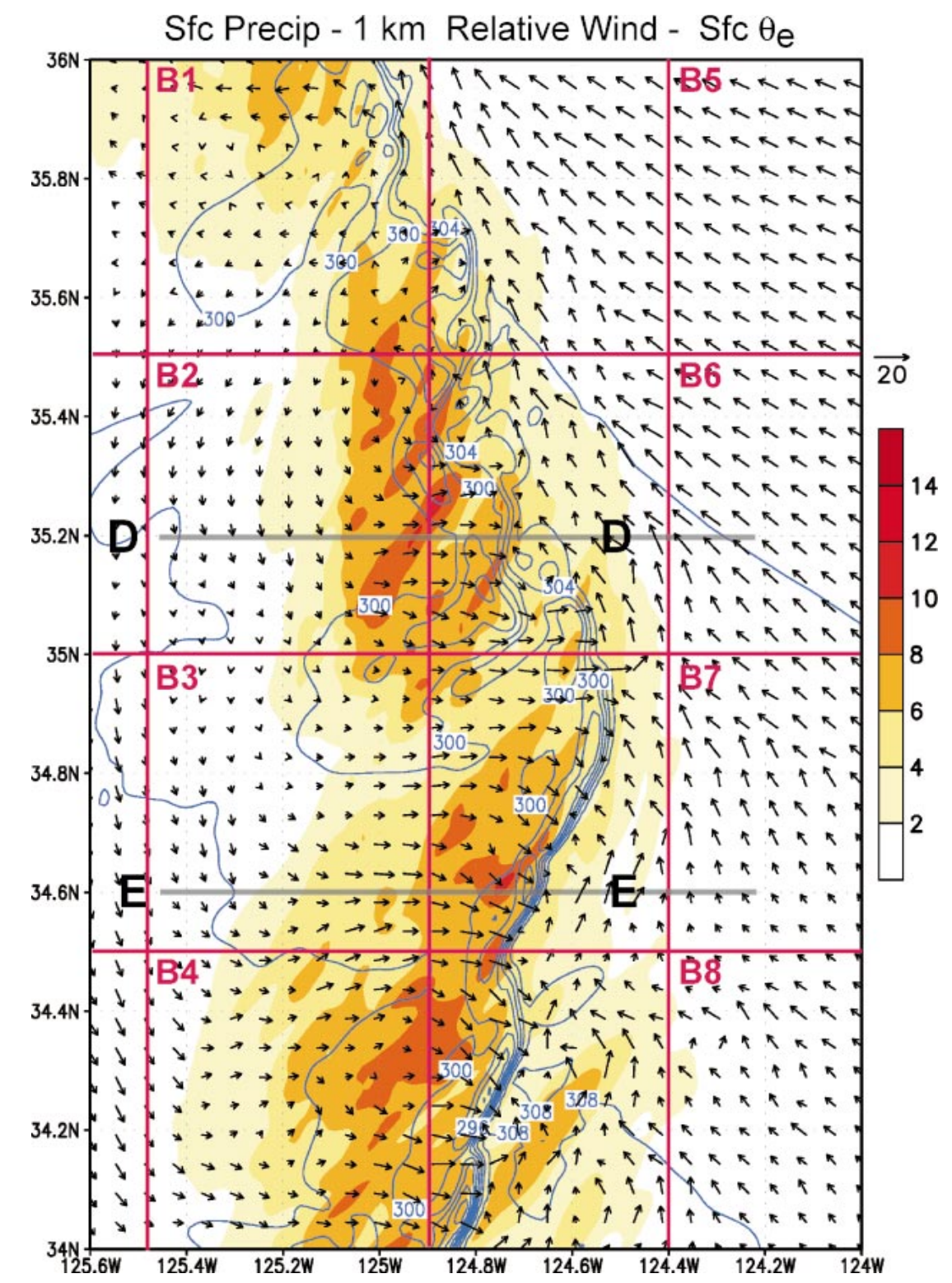

FIG. 21. Horizontal plot of model surface equivalent potential temperature (solid contours, every $2 \mathrm{~K}$ ) and system relative wind at $1 \mathrm{~km}$ MSL (model system motion $u=12.8 \mathrm{~m} \mathrm{~s}^{-1}, v$ $=15.4 \mathrm{~m} \mathrm{~s}^{-1}$ ) and surface precipitation rate (shaded contours; $\mathrm{mm} \mathrm{h}^{-1}$ ) on the $1.3-\mathrm{km}$ grid at 0600 UTC 19 Feb 2001. The color scale for the precipitation rate shading is shown at right. The scaling vector for a $20 \mathrm{~m} \mathrm{~s}^{-1}$ vector is shown above the precipitation color scale. The boxes labeled B1 through B8 are averaging regions for vertical profiles shown in Fig. 22. The two horizontal shaded lines labeled $\mathrm{D}-\mathrm{D}^{\prime}$ and $\mathrm{E}-\mathrm{E}^{\prime}$ are locations of cross sections shown in Fig. 24.

along the leading edge of the precipitation in a narrow ribbon. Minimum $\theta_{e}$ within the ribbon associated with the strongest surface precipitation was $\sim 296 \mathrm{~K}$, a deficit of $\sim 12 \mathrm{~K}$ from the surface values east of the leading edge of $\sim 308 \mathrm{~K}$. North of the gap region the $\theta_{e}$ deficit was $\sim 8 \mathrm{~K}$, but rather than concentrated in a narrow ribbon the leading edge minimum was more diffuse and extended rearward farther than the deficit south of the NCFR gap.
To evaluate the vorticity balance at the NCFR leading edge, the inner model domain (shown in Fig. 21) was divided into eight regions, four behind the line and four ahead of the line. Each domain included $0.5^{\circ}$ of latitude by $0.6^{\circ}$ of longitude and four domains were located north of the gap (domains labeled B1, B5, B2, and B6), and four to the south (domains B3, B7, B4, and B8). Area mean vertical profiles of $u$ (east-west or crossfrontal wind, $\mathrm{m} \mathrm{s}^{-1}$ ), $v$ (north-south or along-frontal 

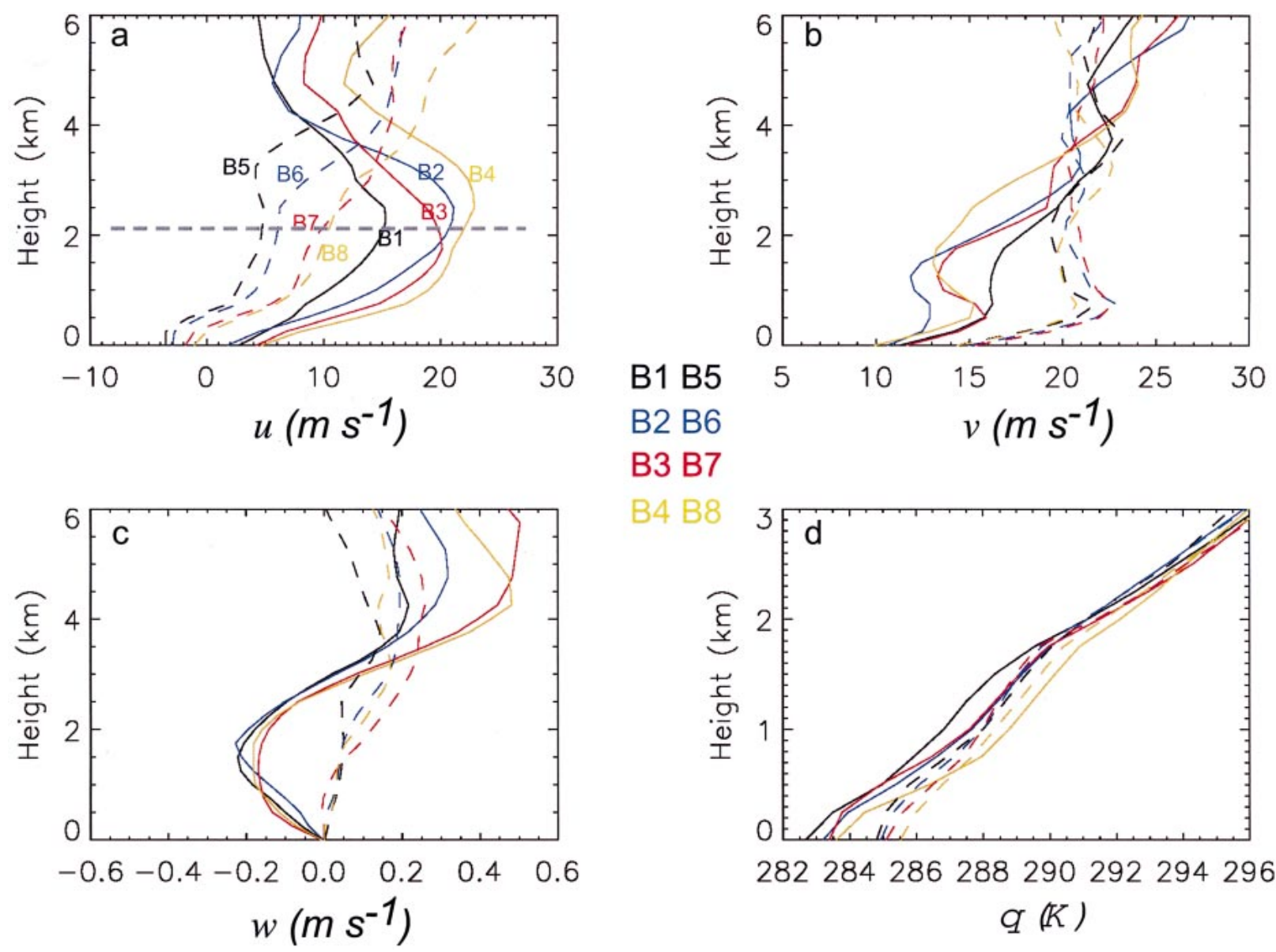

FIG. 22. Model output vertical profiles of (a) mean $u$ (cross frontal) system-relative wind component ( $\mathrm{m} \mathrm{s}^{-1}$ ); (b) mean $v$ (along frontal) system-relative wind component $\left(\mathrm{m} \mathrm{s}^{-1}\right)$, (c) mean vertical motion $w\left(\mathrm{~m} \mathrm{~s}^{-1}\right)$, and (d) potential temperature $(\theta$, $\mathrm{K})$ for the regions shown in Fig. 21. Solid contours are for regions (B1-B4) behind the NCFR while dashed contours are for regions (B5-B8) ahead of the front.

wind, $\left.\mathrm{m} \mathrm{s}^{-1}\right), w$ (vertical velocity, $\mathrm{m} \mathrm{s}^{-1}$ ), and potential temperature (K) are plotted in Fig. 22. Figure 22a shows the mean profile of cross-frontal wind in each of the domains. The low-level cross-frontal wind shear ahead of the front and over the depth $(1.8 \mathrm{~km})$ of the cold air increases from north to south (B5-B8). Similar shear differences were also present in the P-3 aircraft ascent/ descent soundings (Fig. 23), taken about $100 \mathrm{~km}$ north and south, respectively, of the NCFR apex that was located near $35^{\circ} \mathrm{N}$. Although these two aircraft soundings are not strictly on either side of the same gap, Fig. 6 shows that the southernmost sounding (black line in Fig. 23) was just southwest of a gap, while the northernmost sounding (gray line in Fig. 23) was north of another gap. Although synoptic-scale changes in the flow over the $\sim 200 \mathrm{~km}$ between sounding locations could also be a factor (shown in Figs. 7 and 8 as a gradual shift in low-level wind direction from southerlies in the southern part of the NCFR to south-southeasterlies in the north coupled to a gradual drying of the low-level air). This change in prefrontal shear implies that if the circulation due to the cold air were relatively constant, the character of the frontal updraft would vary from an upshear-tilted broad precipitation zone to the north (i.e., $C>\Delta u$; Fig. 16c) to a frontal zone to the south that is either upright $(C \sim \Delta u$; Fig. 16b) and narrow or downshear tilted $(C \ll \Delta u$; Fig. 16a). To the extent that the average wind profiles in B2B6 and B3-B7 represent conditions at the leading edge of the NCFR, the RKW balance arguments applied to the model results are consistent with the P-3 observations across the gap. That is, $\Delta u$ in the lowest $1.8 \mathrm{~km}$ ranges from $\sim 6 \mathrm{~m} \mathrm{~s}^{-1}$ in B6 (north of the gap) to over $\sim 8 \mathrm{~m} \mathrm{~s}^{-1}$ in B7 (south of the gap). Plotted vertical profiles of the alongfront wind component (Fig. 22b) show that the prefrontal low-level jet is also stronger in the middle. The postfrontal regions are dominated by subsidence below about $3 \mathrm{~km}$ (Fig. 22c) and rising motion above. The potential temperature profiles (Fig. 22d) show about $2 \mathrm{~K}$ decreases across the cold air leading edge. Above the cold air $(>2.1 \mathrm{~km})$ the mean profiles of potential temperature are nearly identical.

The model simulation was similar to the P-3 observations in a number of respects. Two model east-west 


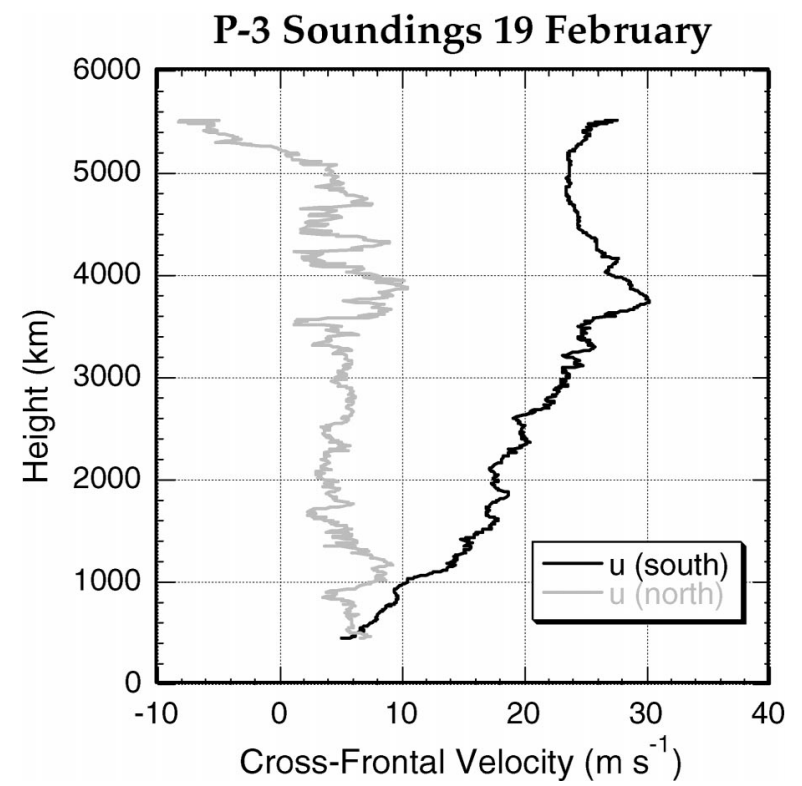

FIG. 23. Cross-frontal wind component $\left(\mathrm{m} \mathrm{s}^{-1}\right)$ from the two P-3 ascent/descent soundings ahead of the NCFR shown in Fig. 6. The gray line is from the northernmost sounding, the black line from the southernmost sounding.

cross sections north and south of the gap near $35^{\circ} \mathrm{N}$ (indicated in Fig. 21 by the two horizontal lines along $34.6^{\circ}$ and $35.2^{\circ} \mathrm{N}$, respectively) are shown in Fig. 24. A nearly erect updraft and relatively narrow precipitation zone characterized the vertical structure of the band segment just south of the break (Figs. 24a,c), while just north of the break a broader updraft and rain zone is present (Figs. 24b,d). Model-computed strong radar reflectivity extended upward to only $\sim 4.5 \mathrm{~km}$, in agreement with the observations, with the maximum lowlevel reflectivity was $\sim 45 \mathrm{dBZ}$, somewhat weaker than the observed maximum of $\sim 55 \mathrm{dBZ}$. Some evidence of weak convective scale downdrafts at the low levels within heavy rain areas are also seen. The strength and depth of the cold air behind the NCFR is approximately the same in the two cross sections, as seen in the areal average of $\theta$ within the $\mathrm{B} 2$ and $\mathrm{B} 3$ regions (Fig. 22). The cloud water field (Fig. 24d) shows a broader cloud region and corresponding updraft zone north of the gap. The wavelike appearance of the cloud region and corresponding updraft zone north of the gap. The wavelike appearance of the cloud water field in Fig. 24d may be a reflection of spurious gravity waves generated by the mismatch of horizontal and vertical grid spacing in the model (Persson and Warner 1991). Concern about this small-scale variability was one of the reasons the model averaging domains (Fig. 21) were as large as possible. Higher-resolution model runs are needed to clarify these points.

\section{Summary and conclusions}

The P-3 radar, dropsonde, and in situ data, as well as MM5 numerical simulations have been used to docu- ment the precipitation and kinematic structure of a strong NCFR well offshore of the U.S. west coast. Many aspects of this NCFR structure have been documented in previous studies, including (a) gaps or breaks in the NCFR's leading-edge narrow precipitation zone (perhaps due to horizontal shearing instability); (b) a strong frontal updraft (maximum vertical velocity $>10 \mathrm{~m} \mathrm{~s}^{-1}$ ) at the leading edge of the advancing cold air, in spite of the absence of potential instability; (c) strong ambient environmental low-level shear of the inflowing air; (d) a low-level jet peaking near $z=1.5 \mathrm{~km}$ AGL ahead of and roughly parallel to the NCFR; and (e) a "rear-inflow" jet of westerly air behind the front peaking near $z=1 \mathrm{~km}$ AGL. Other principal NCFR features documented in this study are as follows:

1) A consistent difference in updraft tilt exists on either side of the NCFR gaps. On the south side of the gap the NCFR is bowed to the east with the strongest near-surface convergence on the western side of the rainfall maximum. The inflowing air thus flows through the heavy precipitation before rising and tilting downshear. To the north of the gap the updraft is erect then transitions to an upshear tilt farther north.

2) Associated with the changes in frontal updraft character are changes in the prefrontal cross-frontal lowlevel wind shear. In regions of downshear tilt there is strengthening of the shear, with upshear tilt there is a weakening of the shear, consistent with RKW theory.

A schematic depiction of the character of the precipitation and updraft structure at several locations across the NCFR gap regions is shown in Fig. 25. Near the middle of an NCFR segment (cross section labeled A$\mathrm{A}^{\prime}$ ), within the precipitation core well-insulated from the circulations associated with the gap regions, the updrafts tend to be erect with narrow rainfall regions. This is an "optimal" vertical shear balance zone as defined by Rotunno et al. (1988) and Parsons (1992). At the south end of the precipitation core nearer to the gap (cross section labeled $\mathrm{B}-\mathrm{B}^{\prime}$ ), is a region where the ambient environmental low-level shear is weak relative to the circulation associated with the cold air, and the updraft is tilted upshear with a broader zone of precipitation. At the northern end of the next core and south of the gap is a region of stronger ambient low-level shear where the updraft tilts downshear with height and the rain falls ahead of the advancing cold air.

While the observations and simulations support the hypothesis that the finescale structure of this NCFR is well approximated by gravity-current dynamics, those dynamics alone do not explain the character of the updraft and precipitation zone. In particular, the slope of the updraft and width of the precipitation zone are not explained by the theory alone. It is the interaction of the gravity current with the ambient cross-front vertical wind shear that determines the character of the updrafts 
model cross section $34.6 \mathrm{~N}$ (south of gap)
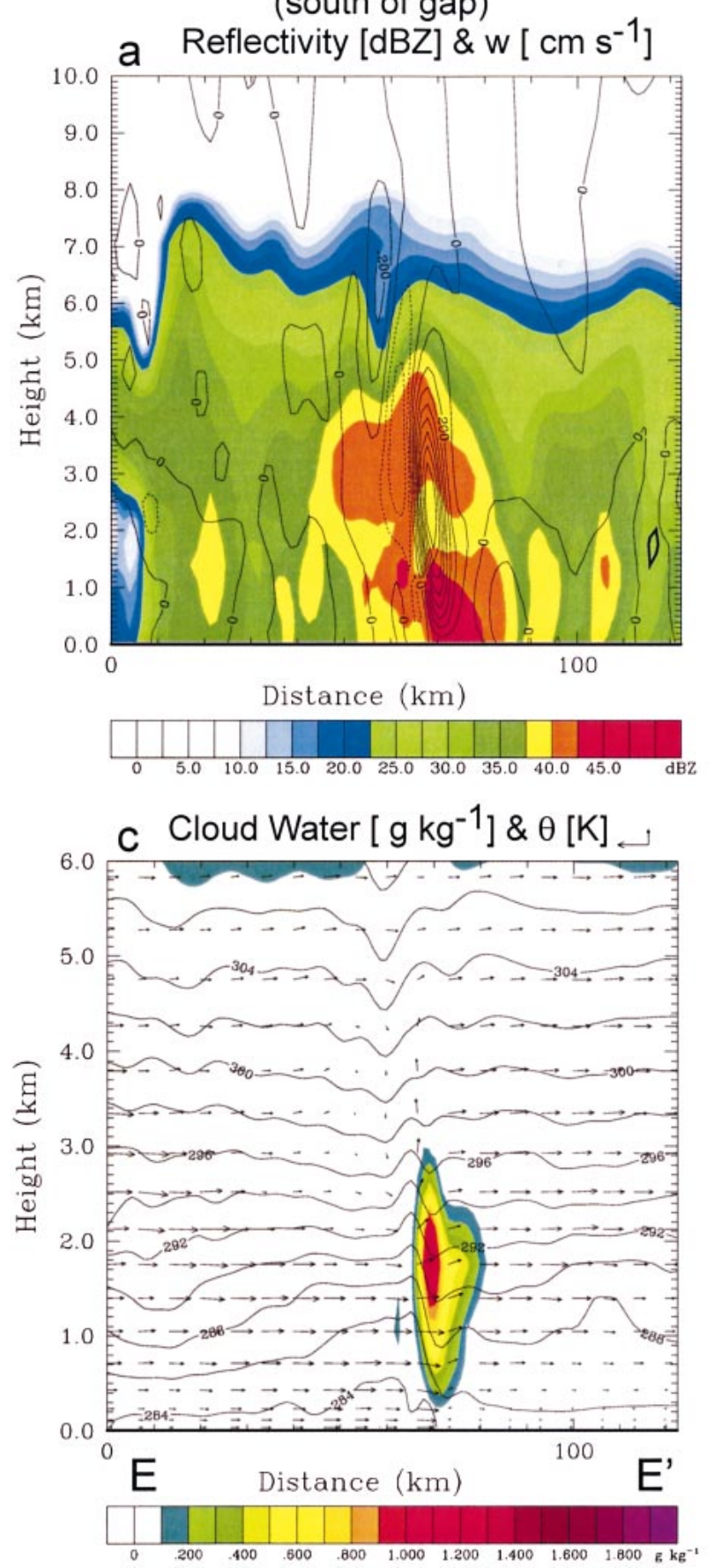

model cross section $35.2 \mathrm{~N}$ (north of gap)

b Reflectivity [dBZ] \& w [ $\left.\mathrm{cm} \mathrm{s}^{-1}\right]$
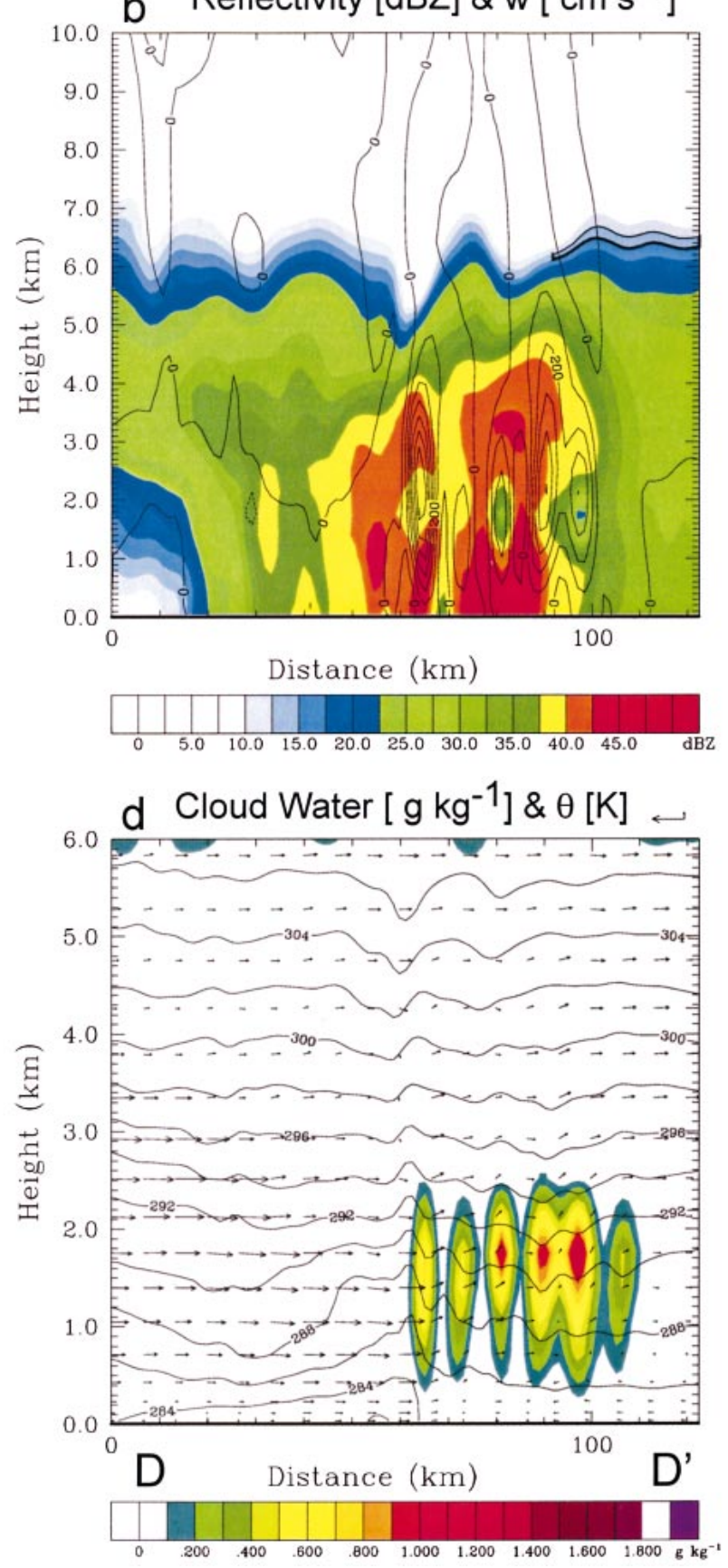

FIG. 24. Model vertical cross section of (a),(b) computed radar reflectivity (dBZ) and vertical velocity (cm s ${ }^{-1}$ ), and (c),(d) cloud water content $\left(\mathrm{g} \mathrm{kg}^{-1}\right)$, system-relative flow in the plane of the cross section, and potential temperature [K] along an east-west line through the NCFR leading edge along $34.6^{\circ} \mathrm{N}$ (a), (c) south of the gap near $35^{\circ} \mathrm{N}$ and $35.2^{\circ} \mathrm{N}$ (b), (d) north of the gap near $35^{\circ} \mathrm{N}$.

and intense precipitation in environments nearly thermally neutral with respect to vertical ascent. Parsons (1992) showed, in a series of two-dimensional numerical simulations, that the change in the slope of modeled NCFR updrafts as vertical shear is varied is also con- sistent with RKW theory. Although the Parsons (1992) simulations were two-dimensional and thus could not address the along-line variations of NCFRs, the results shown here demonstrate the applicability of RKW theory to the structure of observed NCFRs. Although RKW 


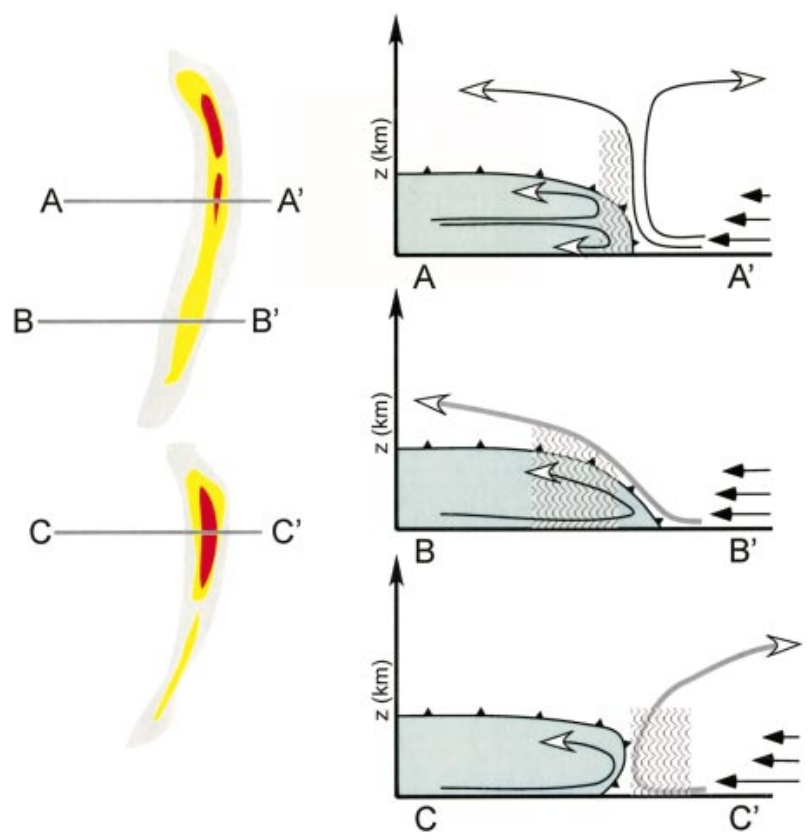

FIG. 25. Schematic depiction of the relationship between rainfall location, updraft location and tilt, and low-level vertical shear of the ambient flow at various locations along the NCFR. The horizontal reflectivity depiction of the NCFR showing a predominant break is shown at left. The locations of three vertical cross sections are indicated by the lines $\mathrm{A}-\mathrm{A}^{\prime}, \mathrm{B}-\mathrm{B}^{\prime}$, and $\mathrm{C}-\mathrm{C}^{\prime}$. Schematic vertical circulation and structure is shown for the three cross sections at right. The low-level shear of the ambient environmental flow is indicated by the arrows at right in the vertical cross sections. Locations of rainfall maxima are indicated by the shaded regions on the cross sections.

theory stresses the role of vorticity balance between the ambient wind shear and the circulation associated with the advancing cold air, the observations and model results described here indicate that, despite the heavy rain at the NCFR leading edge, the cold air strength and depth does not vary significantly across the gap regions. Lack of cold air variation across the gap is probably not surprising given the near-saturated condition of the air below $800 \mathrm{hPa}$ and the resultant ineffectiveness of rain evaporation to contribute significantly to strengthen the cold air. Rather, it is the prefrontal cross-line flow that seems to have the greatest variation along the NCFR and accounts for the differences in updraft and precipitation character. Left unaddressed by this study is why this prefrontal flow behaves as it does. It is speculated that the role played by hydrodynamic (i.e., barotropic) instability may be important, but much more work is required to quantitatively assess the applicability of this mechanism.

The findings presented here suggest that the mechanism for gap maintenance is not self-sustaining. Once the gap forms (due to hydrodynamic instability or some other mechanism) the convection along the bow-shaped segment to the south of the gap would eventually weaken with time compared to the erect or upshear-tilted convection north of the gap, since the inflow sustaining the updraft (to the south) would flow through the heavy rainfall. Rain-induced cooling of the inflow air would reduce whatever small amount of instability exists in the environment. That the gaps exists for such a long period in the simulation is probably a testament to the near-saturated condition within the inflow. The P-3 radar observations of this NCFR suggest that the gaps did not persist more than several hours. Older gaps filled and newer ones developed during the 5-h period of investigation.

This study, along with the studies of Braun et al. (1997), Yu and Smull (2000), and Wakimoto and Bosart (2000), have shown the utility of employing instrumented aircraft to investigate the three-dimensional mesoscale structure and behavior of oceanic frontal rainbands. Although continental squall lines and frontal bands often exhibit bow-shaped features (Johns 1993; Przybylinski 1995; Weisman 1993) it is not known if bows are associated with changes in environmental shear and updraft slope as exhibited by the NCFR studied here. Future aircraft investigations of NCFRs should address the evolution of NCFR breaks by focusing on repeated passes around a single break (perhaps using "box" patterns) for several hours. This more continuous data would permit monitoring the strength of the cold air behind the gap and convective core regions and would facilitate the generation of hypotheses concerning the mechanisms responsible for gaps and their evolution.

Acknowledgments. We wish to acknowledge the efforts of the NOAA P-3 flight crews from the NOAA/ Aircraft Operations Center in Tampa, Florida, who executed the flight patterns used in this study. In particular, we acknowledge the work of the flight director, Tom Shepherd, and the radar engineer, James Barr. Without the dedication and enthusiastic support of the AOC crew for our scientific endeavors, the collection of airborne Doppler radar data near hazardous weather systems would not be possible. Robert Hueftle was instrumental in development of the Doppler wind synthesis and display software. Editing of the radar data was accomplished with the NCAR/SOLO software package provided by Dick Oye of NCAR/ATD. We are grateful to Morris Weisman of NCAR for stimulating discussions of NCFR and squall-line dynamics, as well as for providing Fig. 16. The manuscript was greatly improved through the critical comments provided in reviews by Carl Hane and David Schultz of NOAA's National Severe Storms Laboratory, and Paul Neiman of NOAA's Environmental Technology Laboratory.

\section{REFERENCES}

Atlas, D., R. C. Srivastava, and R. S. Sekhon, 1973: Doppler radar characteristics of precipitation at vertical incidence. Rev. Geophys. Space Phys., 11, 1-35. 
Braun, S. A., R. A. Houze Jr., and B. F. Smull, 1997: Airborne dualDoppler observations of an intense frontal system approaching the Pacific Northwest coast. Mon. Wea. Rev., 125, 3131-3156.

Brown, S. A., J. D. Locatelli, M. T. Stoelinga, and P. V. Hobbs, 1999: Numerical modeling of precipitation cores on cold fronts. $J$. Atmos. Sci., 56, 1175-1196.

Burgess, D. W., and L. R. Lemon, 1990: Severe thunderstorm detection by radar. Radar in Meteorology: Battan Memorial Volume, D. Atlas, Ed., Amer. Meteor. Soc., 619-647.

Carbone, R. E., 1982: Severe frontal rainband. Part I: Stormwide dynamic structure. J. Atmos. Sci., 39, 258-279.

Charba, J., 1974: Application of gravity current model to analysis of squall-line gust front. Mon. Wea. Rev., 102, 140-156.

Chen, C., C. H. Bishop, G. S. Lai, and W.-K. Tao, 1997: Numerical simulations of an observed narrow cold-frontal rainband. Mon Wea. Rev., 125, 1027-1045.

Dudhia, J., 1993: A nonhydrostatic version of the Penn State-NCAR mesoscale model: Validation tests and simulation of an Atlantic cyclone and cold front. Mon. Wea. Rev., 121, 1493-1513.

Grell, G. A., J. Dudhia, and D. R. Stauffer, 1995: A description of the fifth-generation Penn State/NCAR mesoscale model (MM5). NCAR Tech. Note NCAR/TN-398 + STR, 138 pp. [Available from NCAR Publications Office, P.O. Box 3000, Boulder, CO 80307-8000.]

Haurwitz, B., 1949: The instability of wind discontinuities and shear zones in planetary atmospheres. J. Meteor., 6, 200-206.

Hobbs, P. V., 1978: Organization and structure of clouds and precipitation on the mesoscale and microscale in cyclonic storms. Rev. Geophys. Space Phys., 16, 741-755.

- and K. R. Biswas, 1979: The cellular structure of narrow cold frontal rainbands. Quart. J. Roy. Meteor. Soc., 105, 723-727.

—_, and P. O. G. Persson, 1982: The mesoscale and microscale structure and organization of clouds and precipitation in midlatitude cyclones. Part V: The substructure of narrow cold frontal rainbands. J. Atmos. Sci., 39, 280-295.

Houze, R. A., Jr., P. V. Hobbs, K. R. Biswas, and W. M. Davis, 1976 Mesoscale rainbands in extratropical cyclones. Mon. Wea. Rev. 104, 868-878.

James, P. K., and K. A. Browning, 1979: Mesoscale structure of line convection at surface cold fronts. Quart. J. Roy. Meteor. Soc., 105, 371-382.

Johns, R. H., 1993: Meteorological conditions associated with bow echo development in convective storms. Wea. Forecasting, 8 , 294-299.

Jorgensen, D. P., P. H. Hildebrand, and C. L. Frush, 1983: Feasibility test of an airborne pulse-Doppler meteorological radar. J. Climate Appl. Meteor., 22, 744-757.

_, T. Matejka, and J. D. DuGranrut, 1996: Multi-beam techniques for deriving wind fields from airborne Doppler radars. Meteor. Atmos. Phys., 59, 83-104.

- M. A. LeMone, and S. B. Trier, 1997: Structure and evolution of the 22 February 1993 TOGA COARE squall line: Aircraft observations of precipitation, circulation, and surface energy fluxes. J. Atmos. Sci., 54, 1961-1985.

- T. R. Shepherd, and A. Goldstein, 2000: A dual-pulse repetition frequency scheme for mitigating velocity ambiguities of the NOAA P-3 airborne Doppler radar. J. Atmos. Oceanic Technol., 17, 585-594.

Joss, J., and A. Waldvogel, 1970: Raindrop size distribution and
Doppler velocities. Preprints, 14th Conf. on Radar Meteorology, Tucson, AZ, Amer. Meteor. Soc., 153-156.

Klemp, J. B., and R. B. Wilhelmson, 1978: The simulation of threedimensional convective storm dynamics. J. Atmos. Sci., 35, 1070-1096.

Koch, S. E., 1984: The role of an apparent mesoscale frontogenetical circulation in squall line initiation. Mon. Wea. Rev., 112, 20902110.

, 1999: Comments on "Numerical simulations of an observed narrow cold-frontal rainband." Mon. Wea. Rev., 127, 252-257.

_ and P. J. Kocin, 1991: Frontal contraction processes leading to the formation of an intense narrow rainband. Meteor. Atmos. Phys., 46, 123-154.

Lafore, J.-P., and M. W. Moncrieff, 1989: A numerical investigation of the organization and interaction of the convective and stratiform regions of tropical squall lines. J. Atmos. Sci., 46, 521544

Leise, J. A., 1981: A multidimensional scale-telescoped filter and data extension package. NOAA Tech. Memo. ERL WPL-82, 18 pp. [NTIS PB82-164104.]

Locatelli, J. D., J. E. Martin, and P. V. Hobbs, 1995: Development and propagation of precipitation cores on cold fronts. Atmos. Res., 38, 177-206.

Matejka, T. J., R. A. Houze Jr., and P. V. Hobbs, 1980: Microphysics and dynamics of the clouds associated with mesoscale rainbands in extratropical cyclones. Quart. J. Roy. Meteor. Soc., 106, 2956.

O'Brien, J. J., 1970: Alternative solutions to the classical vertical velocity problem. J. Appl. Meteor., 9, 197-203.

Parsons, D. B., 1992: An explanation of intense frontal updrafts and narrow cold-frontal rainbands. J. Atmos. Sci., 49, 1810-1825.

— C. G. Mohr, and T. Gal-Chen, 1987: A severe frontal rainband. Part III: Derived thermodynamic structure. J. Atmos. Sci., 44, $1615-1631$

Persson, P. O. G., and T. T. Warner, 1991: Model generation of spurious gravity waves due to the inconsistency of the vertical and horizontal resolution. Mon. Wea. Rev., 119, 917-935.

Przybylinski, R. W., 1995: The bow echo: Observations, numerical simulations, and severe weather detection methods. Wea. Forecasting, 10, 203-218.

Rotunno, R., J. B. Klemp, and M. L. Weisman, 1988: A theory for strong, long-lived squall lines. J. Atmos. Sci., 45, 463-485.

Rutledge, S. A., and P. V. Hobbs, 1984: The mesoscale and microscale structure and organization of clouds and precipitation in midlatitude cyclones. Part XII: A diagnostic modeling study of precipitation development in narrow cold-frontal rainbands. $J$. Atmos. Sci., 41, 2949-2972.

Simpson, J. E., and R. E. Britter, 1980: A laboratory model of an atmospheric mesofront. Quart. J. Roy. Meteor. Soc., 106, 485500.

Wakimoto, R. M., and B. L. Bosart, 2000: Airborne radar observations of a cold front during FASTEX. Mon. Wea. Rev., 128, 2447 2470.

Weisman, M. L., 1993: The genesis of severe, long-lived bow echoes. J. Atmos. Sci., 50, 645-670.

Yu, C.-K., and B. F. Smull, 2000: Airborne Doppler observations of a landfalling cold front upstream of steep coastal orography. Mon. Wea. Rev., 128, 1577-1603.

Zhang, D.-L., and R. A. Anthes, 1982: A high-resolution model of the planetary boundary layer-Sensitivity tests and comparisons with SESAME-79 data. J. Appl. Meteor., 21, 1594-1609. 